\title{
Dynamics of High-Speed Railway Bridges: Review of Design Issues and New research for Lateral Dynamics
}

\author{
J.M. Goicolea and P. Antolin
}

\section{Summary}

The dynamic effects of high-speed trains on viaducts are important issues for the design of the structures, as well as for the consideration of safe running conditions of the trains. In this work we start by reviewing the relevance of some basic design aspects. The significance of impact factor envelopes for moving loads is considered first. Resonance which may be achieved for high-speed trains requires dynamic analysis, for which some key aspects are discussed. The relevance of performing a longitudinal distribution of axle loads, the number of modes taken in analysis, and the consideration of vehicle-structure interaction are discussed with representative examples.

The lateral dynamic effects of running trains on bridges is of importance for laterally compliant viaducts, such as some very tall structures erected in new high-speed lines. The relevance of this study is mainly for the safety of the traffic, considering both internal actions such as the hunting motion as well as external actions such as wind or earthquakes [1]. These studies require three-dimensional dynamic coupled vehicle-bridge models, and consideration of wheel to rail contact, a phenomenon which is complex and costly to model in detail. We describe here a fully nonlinear coupled model, described in absolute coordinates and incorporated into a commercial finite element framework [2]. The wheelrail contact has been considered using a FastSim algorithm which provides a compromise between accuracy and computational cost, and captures the main nonlinear response of the contact interface. Two applications are presented, firstly to a vehicle subject to a strong wind gust traversing a bridge, showing the relevance of the nonlinear wheel-rail contact model as well as the dynamic interaction between bridge and vehicle. The second application is to a real HS viaduct with a long continuous deck and tall piers and high lateral compliance [3]. The results show the safety of the traffic as well as the importance of considering features such as track alignment irregularities.

\section{References}

[1] W. Guo, H. Xia, Y. Xu, "Running safety analysis of a train on the Tsing Ma Bridge under turbulent winds", Earthquake Engineering and Engineering Vibration, 9(3): 307-318, 2010.

[2] P. Antolin, J.M. Goicolea, J. Oliva, M.A. Astiz, "Nonlinear train-bridge lateral interaction using a simplified wheel-rail contact method within a finite element framework", Journal of Computational and Nonlinear Dynamics, 2012, In press.

[3] F. Millanes, J. Pascual, M. Ortega, "'Arroyo de las Piedras' viaduct: The first composite steelconcrete high speed railway bridge in Spain", Structural Engineering International, 17(4): 292-297, 2007. 


\section{Introduction}

Traffic loads on railway bridges are a major action to be considered for evaluating the safety and functionality of structures. Not only the traffic loads are larger than for road bridges, they also may produce significant dynamic effects due to their regular spacing. Furthermore, the nature of the guided traffic on rails imposes more stringent safety requirements than for road vehicles, resulting in limitations to deck accelerations and deformations. With the advent of faster trains in new high-speed railways and increased demands on the infrastructure the relevance of these dynamic effects has become one of the key design factors for railway bridges.

In this work we start by reviewing some of the basic features related to the dynamic response of bridges under traffic loads (section 2). Some of these features are key aspects for the design and functionality of structures in the new high speed railway lines, and have been incorporated into the recent engineering codes $[3,4,7,35]$. The discussion here has a conceptual approach, hence the models employed will be simple in order to help in understanding the basic design issues and modelling options.

The basic solution of a moving load on a simply supported bridge [33] involves neglecting the non-suspended mass (wheelsets) as well as the vibrations of the suspended masses, a sufficiently approximate solution for many cases. It is easily obtained that the maximum dynamic increment over static effects for a moving load is $\varphi^{\prime}=77 \%$, using standard notation for railway structures engineering [34]. However significant, this increase may be easily bounded by a factor in the design codes, the so-called impact factor. This has been the basis of the approach followed in engineering codes up to very recently [34], until high-speed trains have arrived.

The new high-speed trains introduce a potentially much greater dynamic effect, the resonant response of the bridge from regularly spaced axle loads at speeds whose effective frequency may coincide with the fundamental frequencies of the structure. Resonance is not adequately covered by an impact coefficient and requires a dynamic analysis of the bridge.

As a result of research carried out in Europe to investigate high speed traffic actions [11] the new codes for design of railway bridges take into account resonant phenomena from traffic, in the Eurocodes [3], UIC code [35] or Spanish code [7]). In addition to conservative static load models (LM71) and impact factor envelopes $(\Phi)$ they prescribe dynamic analyses to check resonance under certain circumstances. Furthermore they define a High Speed Load Model (HSLM) which provides a dynamic envelope for European high-speed trains and enables interoperability within the transEuropean network [13].

In general, it is unlikely that the structural Ultimate Limit States (ULS) would be reached from dynamic traffic actions in bridges designed according to modern standards. More often, the critical issues are Service Limit States (SLS) [21] such as the maximum vertical accelerations of the bridge deck. This limit for ballasted track is $a_{\max }=3.5 \mathrm{~m} / \mathrm{s}^{2}$ [4], in order to avoid risk of destabilization of the ballast and unacceptable safety risks to the railway traffic. High levels of acceleration are generally 
observed in short span bridges, due to two reasons: the low overall mass of the bridge, and the fact that the resonant action of the axles (bogies) may be more pronounced for span lengths shorter than the vehicles.

In section 3 this paper deals with lateral dynamics of vehicles on viaducts. This proves to be a phenomenon which may be significant in some cases and for which a coupled full vehicle-structure interaction model must be employed. The interest for this study originates from the observation of significant lateral vibrations in some European railway bridges, with metallic open deck sections, high lateral compliance and consequently low lateral eigenfrequencies. These vibrations affect the train as well as the structure, and were studied under the auspices of UIC and ERRI [10]. The conclusions of this work have resulted in design limits for railway bridges incorporated in the structural Eurocodes and UIC codes $[4,35]$.

A different type of railway structures with high lateral compliance in relative terms are the long continuous viaducts with high piers erected in some high-speed railway lines. Several such viaducts form part of the new Spanish HS lines [20]. In principle these viaducts are not affected by the conclusions of the ERRI studies cited above; however, they also have low frequencies for lateral vibration, but associated in this case with modes of very long wavelengths. In spite of the above, some uncertainties remain about the lateral response of these viaducts, being one of the objects of the present work.

Lateral oscillations may arise from self-excited causes: track alignment irregularities, nosing motion of the wheelsets, deck torsion specially on double track decks, lateral bending of piers, or centrifugal forces. Another obvious origin is external actions, mainly cross winds and earthquakes. It becomes important to evaluate the safe running conditions under these circumstances, such as the characteristic wind curves (CWC) [14].

In this work we propose coupled train-bridge dynamic interaction models for evaluating the running safety of trains over railway viaducts. The models for these problems include the following ingredients [39]: 1) dynamic model for structure subsystem; 2) dynamic model for the vehicle subsystem; 3) description of track irregularity profiles; 4) wheel-rail contact models; and 5) adequate numerical solution algorithms for the equations.

Most of the existing approaches to this problem assume linear models both for the structure subsystem and also for the vehicle multibody system [30, 36-40]. In these models quadratic velocity terms, such as gyroscopic effects, are also neglected. Some approaches which consider nonlinear effects for vehicle and structures have been proposed by [31,32], and in [22], where a linear model is used for the vehicle with additional gyroscopic terms included for the wheelsets.

In this work a fully nonlinear coupled model is proposed for vehicle-structure vertical and lateral dynamic models. Vehicles are considered as fully three-dimensional multibody systems, and the bridge structure is modeled by means of finite elements. The model is developed in a general and modular and it may be easily implemented within an existing finite element analysis software with multibody capabilities. For 
this work Abaqus [28] finite element framework has been used. Both subsystems (bridge and vehicles) are described with coordinates in absolute reference frames, as opposed to alternative approaches which describe the multibody system with coordinates relative to the base bridge motion. This facilitates the full consideration of nonlinear inertia terms, without introducing additional difficulties for the structural mechanical behavior [27].

Contrary to the majority of existing models for train-bridge dynamic interaction, the formulation described here is capable of full consideration of geometrical and material nonlinearities both in the structural subsystem (bridge) and in the multibody subsystem (vehicle). The approach for wheel-rail geometrical interaction and mechanical contact model is fully nonlinear as well, not being limited neither to constant conicity assumptions nor to linearized elastic contact forces. The particular model reported in this work involves some simplifying assumptions that will be described below.

In the rest of this paper we discuss first the dynamic response of bridges in section 2, reviewing the "impact" action of moving loads, resonance, and models available for dynamic analysis. Following, in section 3 we describe the models for lateral dynamics of vehicles on viaducts. Two representative applications will be presented in section 4 . Finally, some concluding remarks are summarised in section 5.

\section{Dynamic response of bridges}

\subsection{Dynamic response to moving load}

The solution to a moving load on a simply supported bridge is well established and available in closed form under certain assumptions. However, it is interesting to review for several reasons. Firstly it provides a basis for defining a dynamic factor (or impact factor) for design. Additionally, the closed form solution helps to identify clearly the characteristics of the dynamic behavior.

From the dynamic equation of vibration of a beam, the solution may be performed with a modal analysis [33], in which we shall take only the fundamental mode of vibration of frequency $f_{0}=\omega_{0} / 2 \pi$ (further down we shall consider the implications of taking more modes). For a load at constant speed $v$ the wavelength is defined as $\lambda=v / f_{0}$. Additionally, for a bridge of span $L$ a non-dimensional parameter $\alpha$ for the load velocity may be defined as:

$$
\alpha=\frac{\lambda}{2 L}=\frac{v}{2 f_{0} L} .
$$

The displacement time history response at the center of the span, in terms of the maximum static response $y_{s}=P L^{3} / 48 E I \approx 2 P L^{3} / \pi^{4} E I$ and considering some simplifications valid for small damping $(\zeta \ll 1)$ is:

$$
y(t)=\frac{y_{s}}{1-\alpha^{2}}\left[\sin \left(\alpha \omega_{0} t\right)-\alpha \mathrm{e}^{-\zeta \omega_{0} t} \sin \left(\omega_{0} t\right)\right],
$$


where the first term within the brackets is due to the excitation from the external load and the second to the free vibration of the bridge.

Figure 1 shows an application for a $L=15 \mathrm{~m}$ simply supported beam-type bridge. The computed dynamic increment at $220 \mathrm{~km} / \mathrm{h}$, with $2 \%$ structural damping, is $\varphi^{\prime}=$ $59 \%$. The critical velocity, for obtaining a maximum dynamic increment, would be in this case $333 \mathrm{~km} / \mathrm{h}$, corresponding to an increase of $\varphi^{\prime}=77 \%$ with no damping. In real bridges, additional dynamic effects must be considered from the irregularities of tracks and wheels (represented by parameter $\varphi^{\prime \prime}$ in UIC standard railway structures engineering notation [34]). However, these are generally of less importance for the bridges: in this case they would only amount up to an additional $0.5 \varphi^{\prime \prime}=2 \%$ dynamic increment for a well maintained track [34].
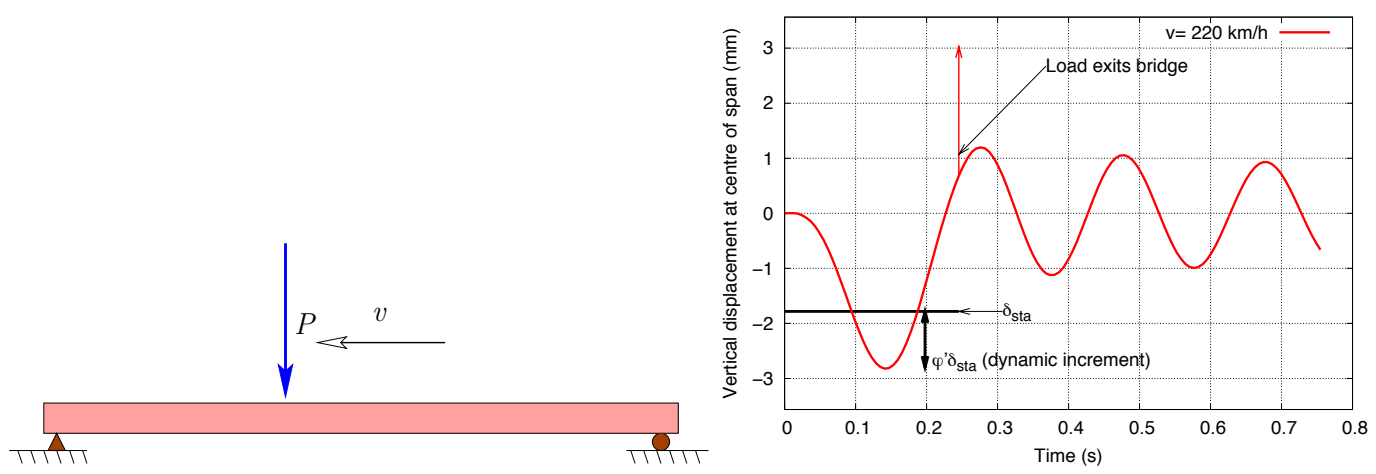

Figure 1: Dynamic increment for moving load on simply supported $L=15 \mathrm{~m}$ bridge, from catalog of ERRI D214 [11], with $v=220 \mathrm{~km} / \mathrm{h}$ and damping $\zeta=0.02$.

The solution (2) is valid during the time the load is on the bridge, under this assumption the maximum $y_{\mathrm{dyn}}$ in terms of $t$ may be computed (for very fast moving loads when the maximum is reached after the load exits the bridge the response is lower). For the most unfavourable case without damping $(\zeta=0)$ the maximum is attained for $\dot{y}=0 \Rightarrow \omega_{0} t=\frac{2 n}{1-\alpha} \pi$, with the result

$$
\frac{y_{\mathrm{dyn}}}{y_{s}}=\frac{1}{1-\alpha^{2}}\left[\sin \left(\frac{\alpha}{1-\alpha} 2 \pi\right)-\alpha \sin \left(\frac{1}{1-\alpha} 2 \pi\right)\right] .
$$

This expression yields an envelope of the dynamic factor with respect to the nondimensional parameter $\alpha$, plotted in figure 2. This envelope curve shows a maximum response for a critical value of $\alpha_{c}$ (and associated critical speed, $v_{c}=2 \alpha_{c} f_{0} L$ ):

$$
\alpha_{c}=0.617 \quad \Rightarrow \quad\left(\frac{y_{\mathrm{dyn}}}{y_{s}}\right)_{\max }=\left(1+\varphi_{\mathrm{dyn}}^{\prime}\right)_{\max }=1.768 .
$$

In figure 2 the code envelope $\varphi^{\prime}{ }_{\mathrm{UIC}}$ is also plotted for comparison, which proves to be sufficiently conservative.

As an example, for the bridges in the D214 ERRI study [11] the maxima of $\varphi_{\text {dyn }}^{\prime}$ correspond to $v_{c}=333 \mathrm{~km} / \mathrm{h}$ for the $L=15 \mathrm{~m}$ bridge and $v_{c}=356 \mathrm{~km} / \mathrm{h}$ for $L=20 \mathrm{~m}$, velocities which may be attained by modern high-speed trains. 


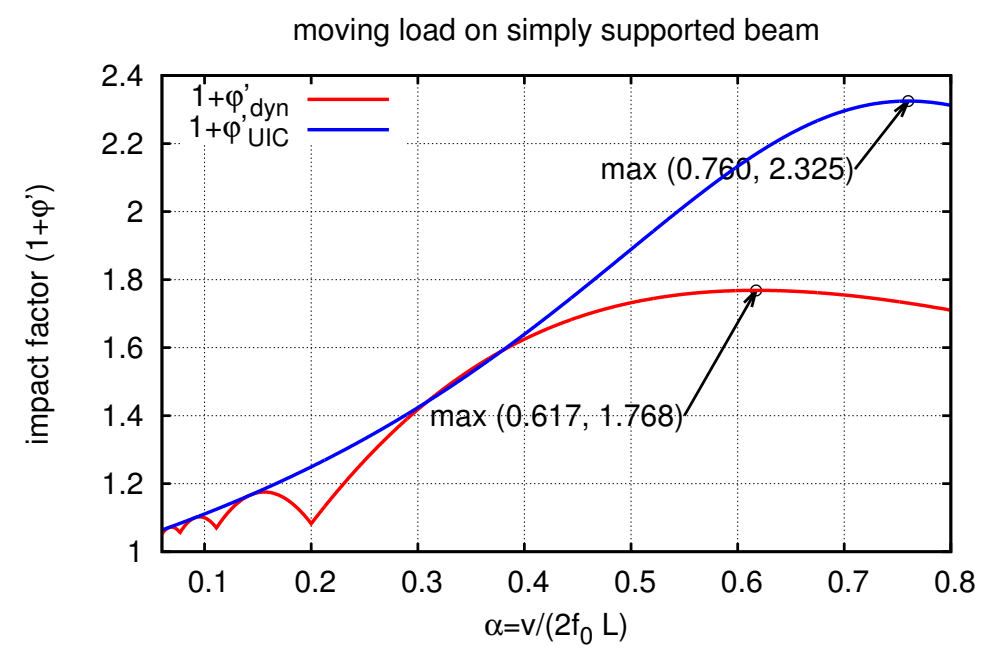

Figure 2: Envelopes of impact coefficient; $\varphi_{\text {dyn }}^{\prime}$ from analytic solution (3) and $\varphi_{\text {UIC }}^{\prime}$ from [35]. The various lobes in $\varphi_{\text {dyn }}^{\prime}$ correspond to slow loads for which the beam performs more than one full oscillation during passage.

\subsection{Dynamic analysis with moving loads}

Resonance in bridges. - In order to motivate the need for more complete dynamic analysis, figure 3 shows some measured results for a bridge in the Madrid-Sevilla HS line, from an AVE S100 (ALSTHOM) train at $220 \mathrm{~km} / \mathrm{h}$. The bridge consists of a
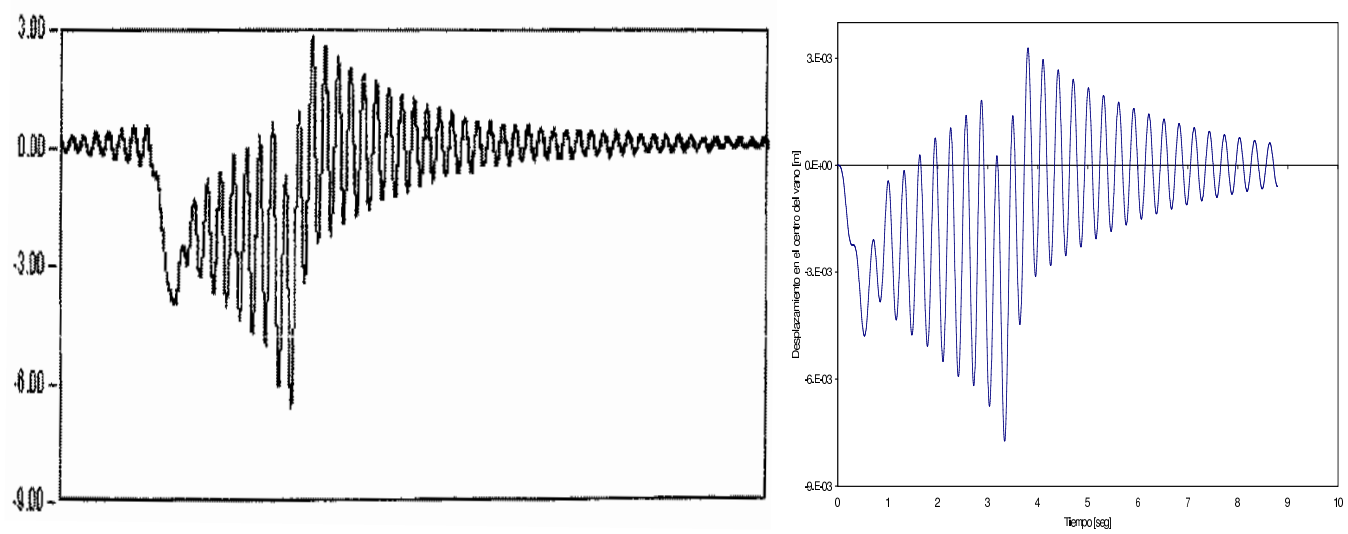

Figure 3: Measured vertical displacement at center of simply-supported span in viaduct over Tajo river, Madrid-Sevilla high-speed line, together with results of simulation with moving load model [9]. AVE S-100 single unit train at $220 \mathrm{~km} / \mathrm{h}$

sequence of simply supported spans with $L=38 \mathrm{~m}$. The measured and computed results show an impact coefficient of approximately $\left(1+\varphi^{\prime}\right)=2.0$, measured with respect to the highest static effects due to the locomotive loads. The effect would have been even greater for a double unit train (approx. $400 \mathrm{~m}$ length). This dynamic 


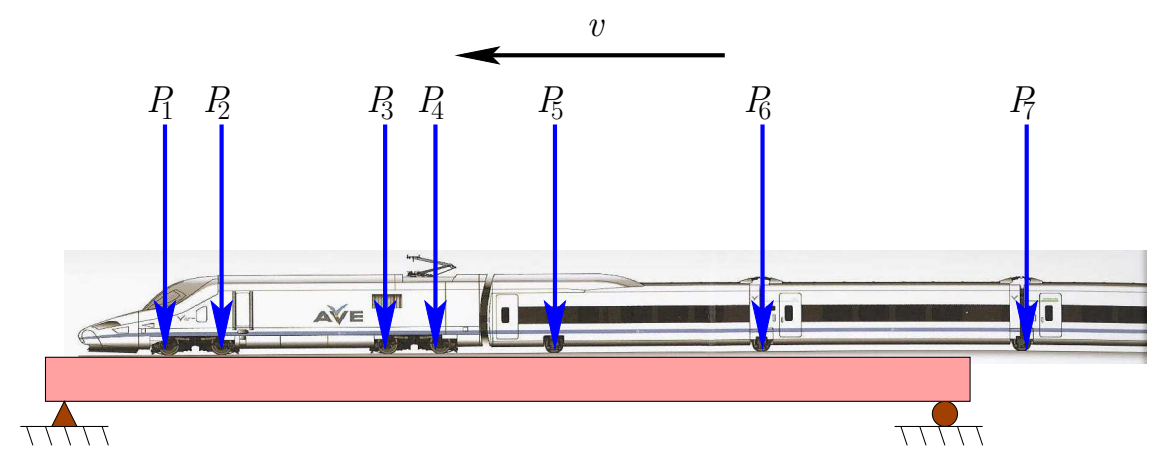

Figure 4: Load sequence from HS train for moving load dynamic analysis, showing AVE S-102 (Talgo) HS train with regularly spaced single axles.

effect is not so much a problem for the Ultimate Limit State (ULS) of the bridge, which in this case is covered by the safety margins embedded in the normative static vertical load envelope LM71 and the impact coefficient $\Phi$ employed for the design [3]. However, in this case the functionality of the bridge was impaired: vibrations induced in the catenary posts proved to be excessive and these had to be relocated into new positions. In other cases the resonant dynamic effects may be even of much greater magnitude, and must be therefore avoided in the design of bridges.

Models for analysis. - The Impact factor is derived from moving load envelopes for analysis of real trains at conventional speeds (i.e. $\leq 200 \mathrm{~km} / \mathrm{h}$ ). It does not cover resonant effects, which may be much greater than moving load effects; in order to consider resonance an impact factor approach would be either unsafe or excessively conservative. For circumstances in which there is a possibility of resonance it is necessary to perform a dynamic analysis of the whole train taking into account the complete load sequence (figure 4). In order to discuss these concepts, we shall consider in what follows models for the simplest case, a straight beam subject only to vertical bending, for which the differential equation governing the dynamics is

$$
\bar{m} \ddot{u}+\left(E I u^{\prime \prime}\right)^{\prime \prime}=p(x, t)=\sum_{k=1}^{N} P_{k}\left\langle\delta\left(x+d_{k}-v t\right)\right\rangle,
$$

for a train with $N$ concentrated axle loads $P_{k}$ with offsets $d_{k}$, where $x$ is the longitudinal coordinate, $u(x)$ the beam vertical displacements, $\bar{m}$ the mass per unit length, and $\delta(\cdot)$ is the Dirac delta function. The brackets $\langle\cdot\rangle$ have the meaning $\langle\delta(\xi)\rangle=\delta(\xi)$ if $0<\xi<L$ (load within bridge) or 0 otherwise. Superposed dots $(\bullet)$ represent time derivatives and primes $\left(\bullet^{\prime}\right)$ derivatives with respect to $x$. This equation may be generalized for arbitrary structures either with 3D beams, torsional effects, shear deformation, or more general continuum-type descriptions. In particular, torsion is added straightforwardly to the above equation.

The solution to equation (5) is obtained in two steps, first in space $(x)$ and then in time $(t)$. For simple cases, such as the simply supported beam, the spatial solution 
can be performed analytically through modal analysis, obtaining uncoupled modal equations for the amplitude of vibration of each mode [6]. Considering mode shapes $\phi_{i}(x)$ and associated circular frequencies $\omega_{i}$ :

$$
M_{i} \ddot{y}_{i}+2 \zeta_{i} \omega_{i} M_{i} \dot{y}_{i}+\omega_{i}^{2} M_{i} y_{i}=\sum_{k=1}^{N} P_{k}\left\langle\phi_{i}\left(x+d_{k}-v t\right)\right\rangle,
$$

where $y_{i}$ is the amplitude for mode $\phi_{i}, M_{i}$ is the corresponding modal mass and $\zeta_{i}$ the damping ratio. These equations may be integrated in time by direct numerical algorithms (either coded directly or available within finite element software).

A more general procedure is to employ finite element (FE) software for the discretization of the dynamic equations in space, enabling solution of fully $3 \mathrm{D}$ problems. The only feature which is special for these dynamic problem, as compared to other structural dynamics problems, is the adequate definition of the actions from the moving loads, which needs an ad-hoc preprocessing. As a result of FE discretization the following matrix system of ordinary differential equations is obtained

$$
\mathbf{M} \ddot{\mathbf{u}}+\mathbf{C u}+\mathbf{K u}=\mathbf{f}(t),
$$

where $\mathbf{M}, \mathbf{C}$ and $\mathbf{K}$ are respectively the mass, damping and stiffness matrices and $\mathbf{f}(t)$ the load vector obtained from the moving loads. At this point within FE software it may be chosen to do a direct time integration of the coupled equations (7) with a numerical scheme, or to perform a modal analysis of the discretised system and obtain numerical mode shapes and frequencies. These will then be available as uncoupled equations identical to (6) and may be integrated in time individually. The modal analysis option has several advantages. The number of modes to consider can be chosen thus avoiding high-frequency components from higher modes, which are not significant for the bridge response. Moreover, the solution is generally much faster. The alternative approach of performing a direct time integration of the complete system provides a more general method, which may be necessary in some cases, for instance to consider nonlinear effects such as contacts.

Example with enhanced impact.- Following we discuss an application, solved with a dynamic moving load analysis. It serves as an example of a case with an enhanced impact effect with respect to the single moving load solution in section 2.1, due to a phenomenon which may be termed "repeated impact". Figure 5 shows the case of an articulated multiple unit train $(M U)$ [29] at the critical moving load velocity $\left(\alpha_{c}=0.617, v_{c}=353 \mathrm{~km} / \mathrm{h}\right)$, together with the quasi-static response neglecting inertial vibration. The impact factor obtained is $\left(1+\varphi^{\prime}\right)=2.45$, clearly larger than that for a moving load (figure 2). We remark the response in this case is not a case of resonance, but does represent a case for which the simple moving load coefficient is not sufficient.

Longitudinal distribution of loads. - The axle loads from railway traffic are transmitted by the track structure, which will perform a longitudinal distribution of these 


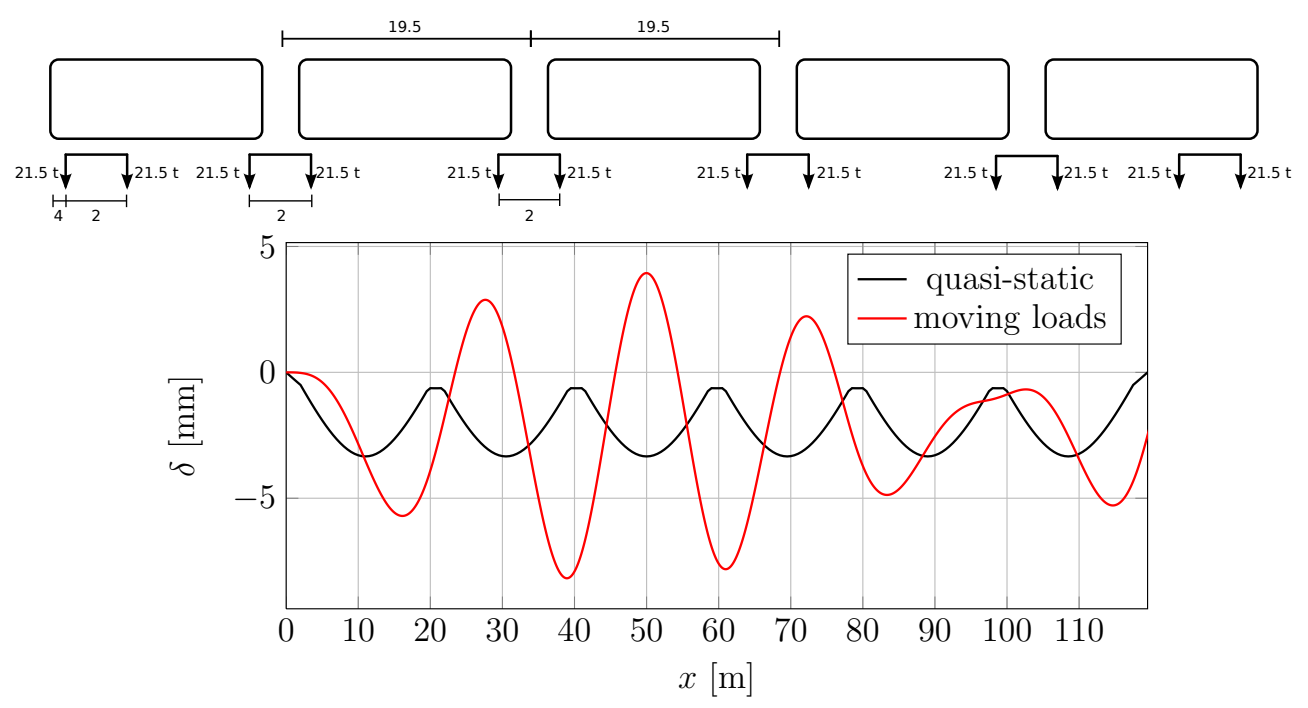

Figure 5: Response for $v=353 \mathrm{~km} / \mathrm{h}$ load model for articulated MU AB_2D [29], 5 coach unit with individual axle loads $P=21.5$ t; vertical displacements at midspan for $L=20 \mathrm{~m}$ bridge from ERRI D214 [11], considering moving loads; The horizontal axis represents the distance $x=v t$ allowing synchronized comparison at different speeds.

loads due to the stiffness of rail, railpads and ballast [12] as they attain the deck of the bridge. This distribution may have some significance for short bridges, as compared to the consideration of concentrated point loads [3]. A reasonable assumption for usual track stiffness is to consider a $\frac{1}{4}-\frac{1}{2}-\frac{1}{4}$ distribution on 3 consecutive sleepers separated $0.60 \mathrm{~m}$. Figure 6 shows a representative example, the maximum acceleration envelope in the bridge deck as a function of train speed for a $10 \mathrm{~m}$ span bridge and a reference MU load model, with a reduction of approximately $10 \%$ in dynamic effects at the critical speed.

Number of modes to consider.- An issue which may be of importance is the number of modes to consider in the modal analysis. Some indications to this purpose are given in the Eurocode [4] for checking accelerations on the bridge deck. For a displacement analysis of a simply supported beam, it may be generally carried out with only the first (fundamental) mode. Acceleration analysis or the extraction of stresses or sectional resultants will often require more modes to be considered.

As an example, we present comparative results for the case of the ERRI D214 $L=30 \mathrm{~m}$ bridge under the ICE3 HS train in figure 7. The fundamental (first symmetric) mode frequency is in this case $f_{1}=3 \mathrm{~Hz}$, and the second symmetric mode is $f_{3}=27 \mathrm{~Hz}$ (the $2^{\text {nd }}$ mode is skew-symmetric and has no influence on mid-span deflections). The analysis is performed here for a resonant velocity. It is clear from figure 7 (left) that for displacements only the fundamental mode is significant. However, a noticeable influence is seen in figure 7 (right) for accelerations from the second symmetric mode. Further modes or even the direct integration with the complete model 

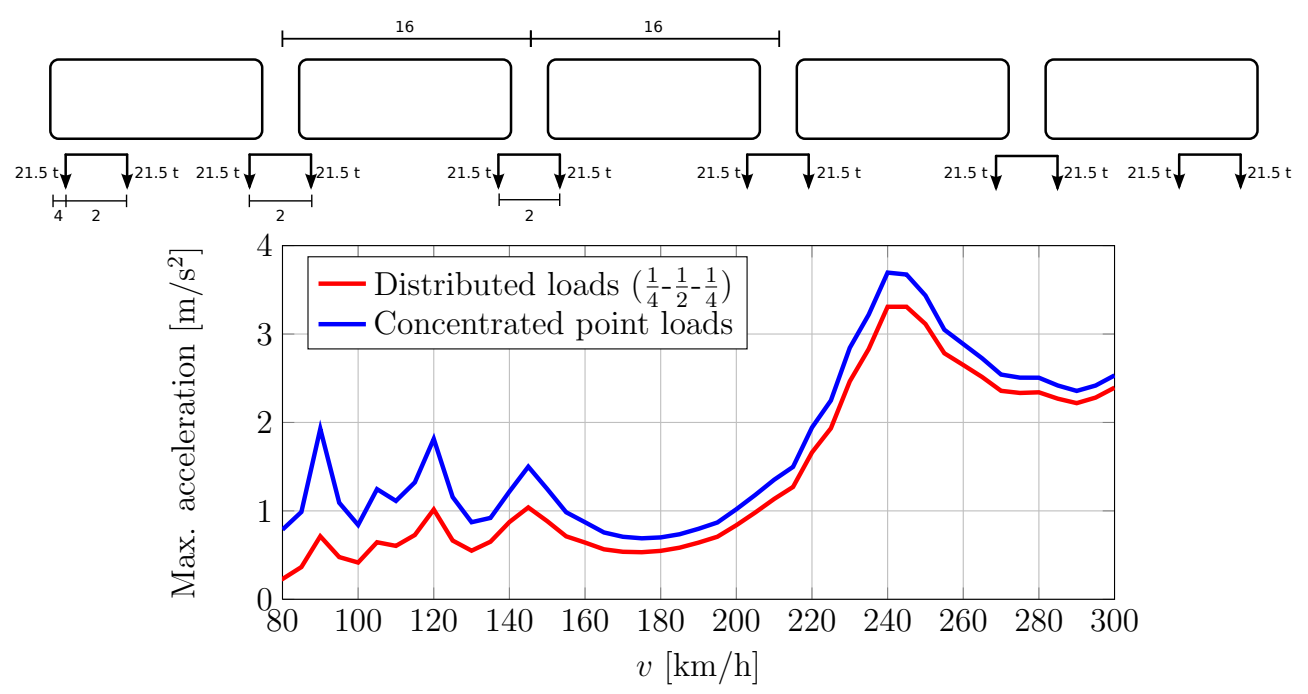

Figure 6: Envelopes for maximum accelerations showing the effect of track load distribution; reference load model for articulated $\mathrm{MU}$ AB_1D [29], $5 \times 5$ coach units with individual axle loads $P=21.5 \mathrm{t}$. Simply supported bridge $L=10 \mathrm{~m}, \bar{m}=12$ $\mathrm{t} / \mathrm{m}, f_{0}=12.464 \mathrm{~Hz}, \zeta=2.2 \%$.
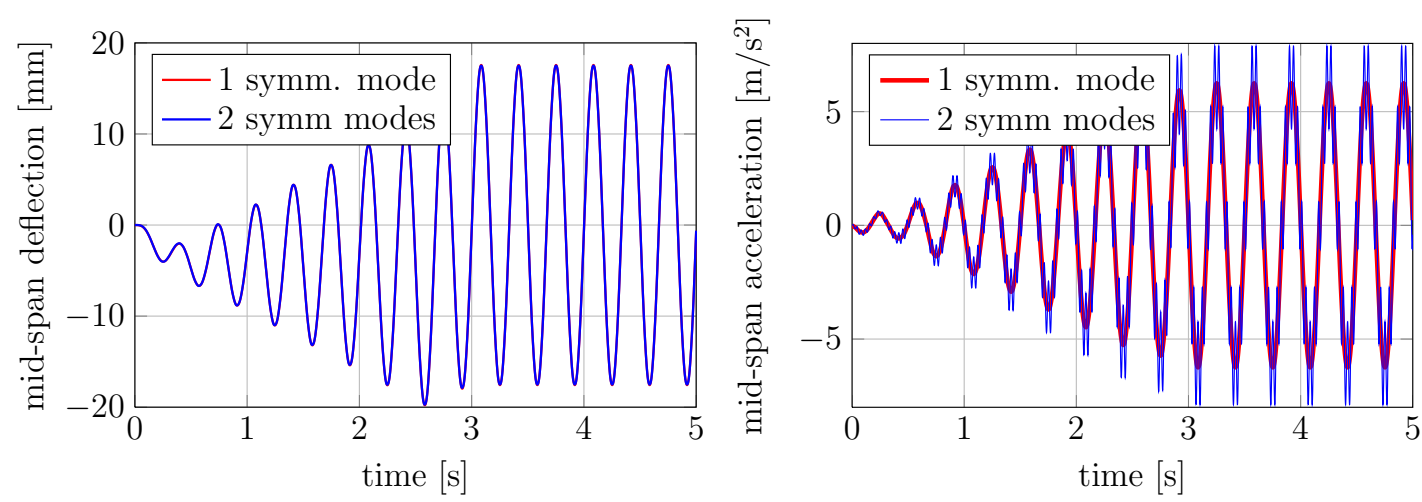

Figure 7: Influence of number of modes for simple bridge, on displacements and accelerations. ICE3 HS train at $v=268 \mathrm{~km} / \mathrm{h}$ on $L=30 \mathrm{~m}$ bridge from ERRI D214 [11]

yield only minor increases to these accelerations.

\subsection{Models with vehicle-structure interaction}

The above models for dynamic analysis consider the traffic actions as moving loads of fixed values, whereas in reality these loads provide from vehicles which have their own dynamics and will not be constant. More realistic approaches include coupled vehiclebridge dynamic models with the interaction between both subsystems. In general, the consideration of interaction with vehicles will allow part of the energy of vibration 

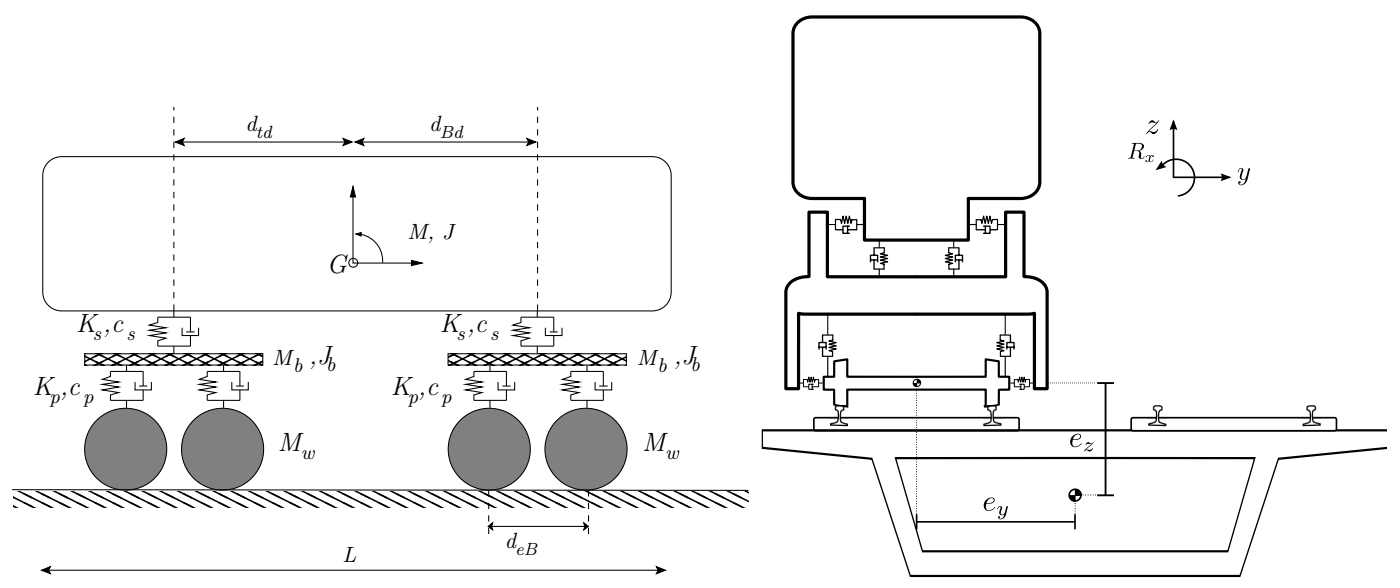

Figure 8: Schematic representation of models for vehicle-bridge interaction

of the bridge to be transferred to the vehicles, and consequently will predict lower vibrations on the bridge.

Vehicle subsystems may be generally considered as rigid bodies, with masses for wheelsets $M_{w}$, bogies $M_{b}$ and Vehicle box $M$, and concentrated springs and dampers, as shown in figure 8. Models for vertical dynamics need include only vertical translation degrees of freedom and pitch rotations for vehicle body or bogies, resulting in relatively simple multibody models. Models for lateral dynamics include transversal displacement and generally also roll and yaw rotations. These need complete 3D descriptions and should be handled with general multibody models, either linear or nonlinear, as described in section 3.

\subsubsection{Simplified Interaction Model}

Often full vehicle-bridge interaction models such as shown in figure 8 are not required, as some parts of the vehicle will not interact with the bridge, depending on the frequencies of vibration. Bodies with frequencies which are very low with respect to the bridge will not be excited by the bridge motion and behave as constant moving loads. Bodies with frequencies which are much higher will behave as added masses.

For railway passenger vehicles under vertical motion one can identify three basic characteristic frequencies for vertical vibration of the vehicle: 1) vibration of wheelsets considering Hertz contact with the rails, in the order of $100 \mathrm{~Hz}$; 2) vibration of bogies on the primary suspension, in the order of $4 \mathrm{~Hz} ; 3$ ) vibration of the vehicle box, in the order of $1 \mathrm{~Hz}$. In practice, the types of bridges which show greater dynamic vibrations have fundamental frequencies in the order of 3 to $7 \mathrm{~Hz}$, hence the interaction will provide mainly from bogie masses and primary suspensions. Wheelset masses behave (from the point of view of bridge dynamics) as rigidly attached to rails, and vehicle box masses as moving loads of fixed value.

For such cases a simplified interaction model is convenient (figure 9): the bridge will be modelled by modal analysis with $i=1 \ldots n$ modes, the train with $j=1 \ldots k$ 
interaction elements (one per wheelset, suspended mass + moving load). Under these
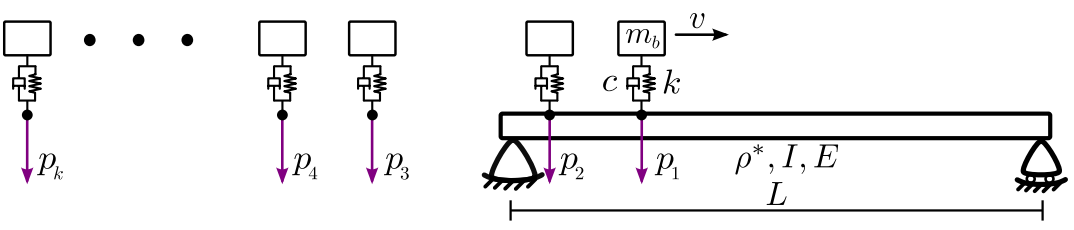

Figure 9: Simplified models for vehicle-bridge interaction including suspended bogie masses and primary suspension

assumptions, the equations for each mode of vibration $\left(\phi_{i}=1 \ldots n\right.$, with amplitudes $\left.y_{i}\right)$ are (details in [9]):

$$
M_{i} \ddot{y}_{i}+C_{i} \dot{y}_{i}+K_{i} y_{i}=\sum_{j=1}^{k}\left\langle\phi_{i}\left(d_{\mathrm{rel}}^{j}\right)\right\rangle\left(p^{j}+m_{b}^{j} \ddot{z}^{j}\right),
$$

and for each interaction element $\left(z_{j}=1 \ldots k\right)$ :

$$
\begin{aligned}
m_{b}^{j} \ddot{z}^{j}+k^{j}\left[z^{j}-\sum_{i=1}^{n} y_{i}\left\langle\phi_{i}\left(d_{\mathrm{rel}}^{j}\right)\right\rangle\right] \\
+c^{j}\left[\dot{z}^{j}-\sum_{i=1}^{n} \dot{y}_{i}\left\langle\phi_{i}\left(d_{\mathrm{rel}}^{j}\right)\right\rangle-\sum_{i=1}^{n} y_{i} v\left\langle\phi_{i}^{\prime}\left(d_{\mathrm{rel}}^{j}\right)\right\rangle\right]=0 .
\end{aligned}
$$

These equations are simple to implement and represent only a minor extension to the moving load modal analysis equations (6), with very small computational cost.

Reduction in predicted dynamic effects from consideration of interaction more relevant in short bridges and with frequencies of the same order as that of the primary suspension, and for critical resonant velocities. As a representative example we show in figure 10 the results as compared to moving load models. The case corresponds to a CAF articulated MU train, whose primary suspension frequency is $f_{1}=5.97$ $\mathrm{Hz}$ on a $L=20 \mathrm{~m}$ bridge with fundamental frequency $f_{0}=4 \mathrm{~Hz}$. The maximum deck accelerations obtained for the critical speed $v=280 \mathrm{~km} / \mathrm{h}$ are $10.9 \mathrm{~m} / \mathrm{s}^{2}$ with moving loads and $7.8 \mathrm{~m} / \mathrm{s}^{2}$ with interaction, a reduction of $\approx 40 \%$. The Envelope of maxima obtained with respect to train speed shows that the reduction obtained with vehicle interaction is relevant for critical resonant velocities, but is not significant for non resonant scenarios.

\section{Lateral dynamics of vehicles on bridges}

\subsection{General features of model}

The consideration of lateral dynamics for the response of railway vehicles on bridges requires three dimensional models, including degrees of freedom for lateral displacement, rolling and yawing in the vehicles. It is also necessary to employ coupled 

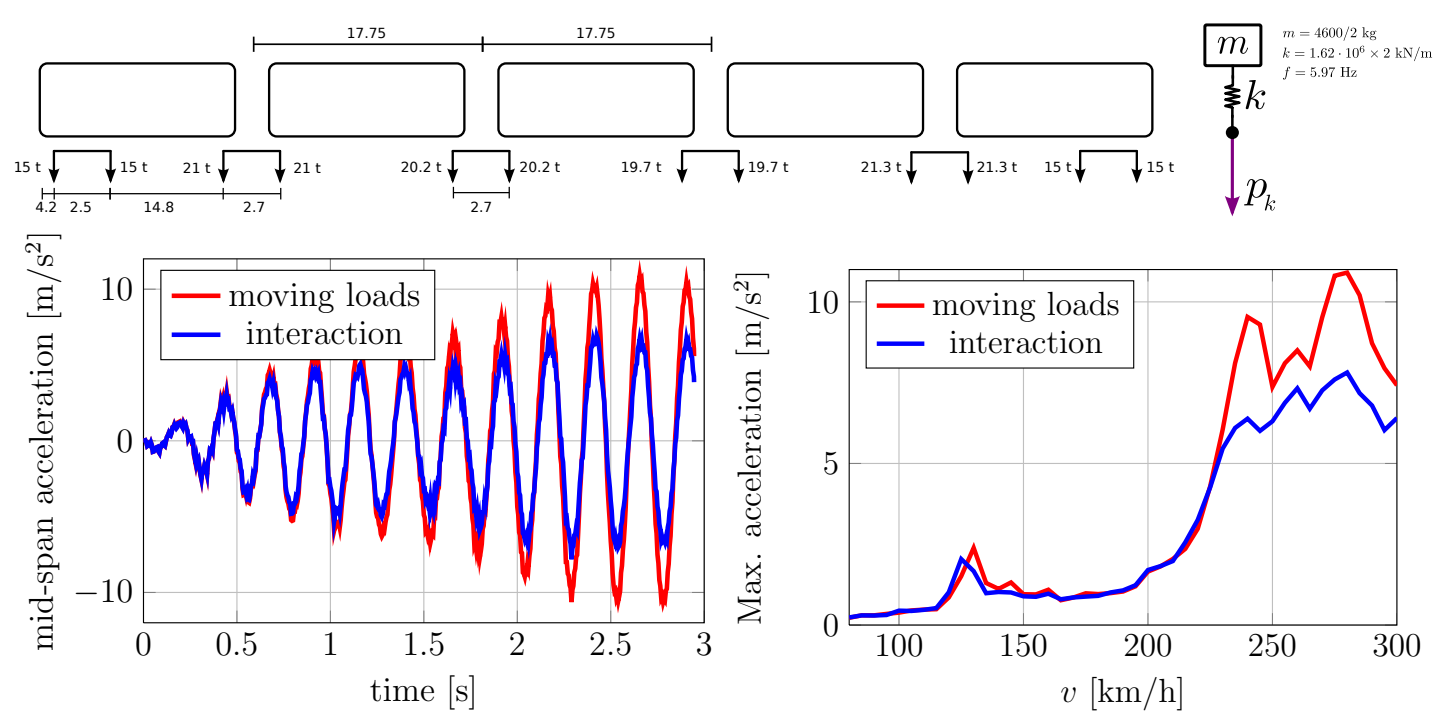

Figure 10: Accelerations obtained with moving loads and with interaction with primary suspension: $L=20 \mathrm{~m}$ bridge ERRI D214 [11], $f_{0}=4 \mathrm{~Hz}, \zeta=1 \%$; CAF TEMD train, primary suspension frequency $f_{1}=5.97 \mathrm{~Hz}$. Time history for resonant critical velocity $v=280 \mathrm{~km} / \mathrm{h}$ (top) and envelope as a function of velocity (bottom).

vehicle-structure models, which must take into account such features as nosing motion of wheelsets on the rails as well as track alignment irregularities. These features give rise to substantially more complex models than those used for vertical dynamics described in the previous section.

In this work a fully nonlinear coupled model is proposed for the lateral dynamic analysis of vehicles on viaducts. Vehicles are considered as three-dimensional multibody systems, and the bridge structure is modeled by means of finite elements. The model is developed in a general and modular way so that it may be easily implemented within an existing finite element analysis software with multibody capabilities. For this work Abaqus [28] finite element framework has been used. Both subsystems (bridge and vehicles) are described with coordinates in absolute reference frames, as opposed to alternative approaches which describe the multibody system with coordinates relative to the bridge motion at the base of the vehicle. This facilitates the full consideration of nonlinear inertia terms, without introducing additional difficulties for the structural mechanical behavior [27].

Contrary to the majority of existing models for train-bridge dynamic interaction, the formulation described here is capable of full consideration of geometrical and material nonlinearities both in the structural subsystem (bridge) and in the multibody subsystem (vehicle). The approach for wheel-rail geometrical interaction and mechanical contact model is fully nonlinear as well, not being limited neither to constant conicity assumptions nor to linearized elastic contact forces. However, the particular model and applications reported here involves some simplifying assumptions that will be described below. 
A key aspect to address is the contact interface between bridge and vehicle, for which several approaches could be followed:

1. A perfectly guided predefined path for the vehicle wheelsets, for the more direct and simplest models; in these contact points between wheels and rails share position and velocity. An assumed hunting movement can be introduced as a prescribed motion of wheelsets $[8,30,36,39]$.

2. Linear models for taking into account relative motion between wheelset and track; these rely on the classical assumption of constant conicity in wheel and rail profiles and simplified contact $[37,38,40]$.

3. Nonlinear models with more detailed treatment of wheel to rail contact, such as proposed in $[22,32]$.

In this work we follow the last option, including a fully nonlinear wheel-rail interaction, based on the elastic contact forces approach [25]. The approach for contact point determination at each wheel may be completely general, however the model here reported employs a contact point determination based on a pre-computed geometric lookup table. A single hertzian contact point [15] is considered at each wheel. The tangential contact is solved by the FastSim algorithm [17]. Following the basic features of the model are summarized. A more detailed description may be found in [2].

\subsection{Kinematics of wheelset and track}

The wheelsets are considered as rigid bodies, within the vehicle multibody subsystem. The bridge deck cross sections are also assumed to be rigid within the structural finite element model, i.e. no distortion of the plane cross section is considered. This assumption is automatically enforced by standard 3D beam-type finite elements. However, both vehicle and bridge can undergo large displacements and rotations. In order to establish the contact interface with sufficient precision a detailed description of the positions and velocities of the wheel and rail points is required, whose key concepts are summarised below. A more general description of multibody kinematics may be found in [23] or more specifically for railway applications in [24,26].

Wheelset kinematics. - The position of a wheel point $A$, such as the wheel-rail contact, at a certain time instant, is defined by (Figure 11)

$$
\boldsymbol{r}_{A}=\boldsymbol{r}_{w}+\boldsymbol{\rho}_{A}=\boldsymbol{r}_{w}+\boldsymbol{\Lambda}_{w} \overline{\boldsymbol{\rho}}_{A}
$$

where $\boldsymbol{r}_{w}$ is the position vector of the wheelset center of mass, $\boldsymbol{\rho}_{A}$ the relative position of the contact point $A, \bar{\rho}_{A}$ the convective vector referred to the body reference system $\left\{w, \boldsymbol{e}_{i}^{w}\right\}$, and $\boldsymbol{\Lambda}_{w}$ the rotation tensor that defines the absolute orientation of the 


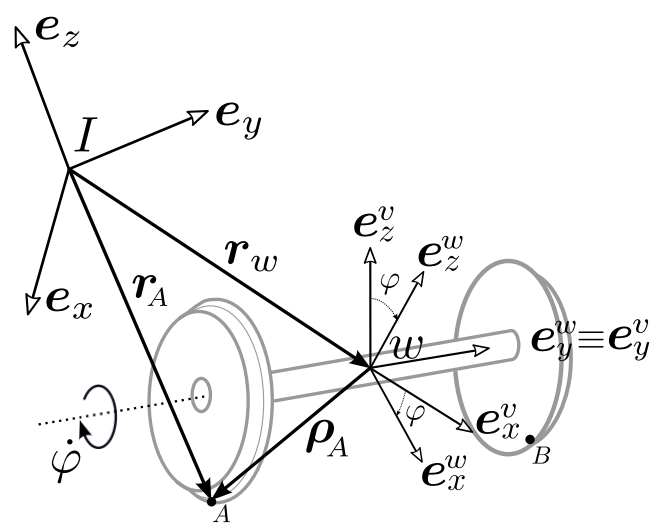

Figure 11: Reference frames and vectors for wheelset kinematics: the inertial reference frame $\left\{I, \boldsymbol{e}_{i}\right\}$; the body reference frame $\left\{w, \boldsymbol{e}_{i}^{w}\right\}$; and an intermediate frame which does not consider wheelset $\operatorname{spin}\left\{w, \boldsymbol{e}_{i}^{v}\right\}$

wheelset. We shall consider that the spin of the wheelset is a given rate $\dot{\varphi}$. It is advantageous to employ an intermediate reference frame $\left\{w, \boldsymbol{e}_{i}^{v}\right\}$ which does not inherit this spin, as in this frame the contact point of one wheel will be a constant vector $\tilde{\boldsymbol{\rho}}_{A}$.

Considering a given parametrization $\boldsymbol{\theta}_{v}$ for rotations (Euler angles, Euler parameters...), the angular velocity $\boldsymbol{\omega}_{w}$ can be expressed in general as

$$
\boldsymbol{\omega}_{w}=\boldsymbol{\omega}_{\varphi}+\boldsymbol{\omega}_{v}=\boldsymbol{\omega}_{\varphi}+\mathbf{G} \dot{\boldsymbol{\theta}}_{v}
$$

where $\mathbf{G}$ is a non-constant matrix operator whose structure depends on the choice of parametrization and whose coefficients depend on the rotation coordinates $\boldsymbol{\theta}_{v}$.

Track kinematics. - We consider a bridge deck section at a position on the deck defined by the longitudinal coordinate $s_{w}$ (Figure 12). The position vector of a point $C$ on the rail, in a similar way as for the wheelset, may be expressed as

$$
\boldsymbol{r}_{C}=\boldsymbol{r}_{b}+\boldsymbol{\Lambda}_{b} \tilde{\boldsymbol{\rho}}_{t}+\boldsymbol{\Lambda}_{t} \overline{\boldsymbol{\rho}}_{C}
$$

where $\boldsymbol{r}_{b}$ defines the position of the reference point on the deck section. Two reference frames are used for the track: the bridge section reference system $\left\{b, \boldsymbol{e}_{i}^{b}\right\}$ which is attached to the deck section at point $b$, and the track reference frame $\left\{t, \boldsymbol{e}_{i}^{t}\right\}$ attached to the track point $t$ located at the mid point between the top of both rails and at the same deck section. $\Lambda_{b}$ and $\Lambda_{t}$ are, respectively, the rotation tensors that relate both reference systems and the inertial frame.

The position of deck section reference point $\boldsymbol{r}_{b}$ is obtained by interpolation of the finite element nodal coordinates along the bridge deck,

$$
\boldsymbol{r}_{b}=\boldsymbol{r}_{b 0}+\mathbf{T}_{d}\left(s_{w}\right) \mathbf{q}^{B},
$$

where $\mathbf{q}^{B}$ is the nodal coordinates vector of the bridge, $\mathbf{T}_{d}\left(s_{w}\right)$ the displacements interpolation operator, consistent with the FE approximation employed, and $\boldsymbol{r}_{b 0}$ the 


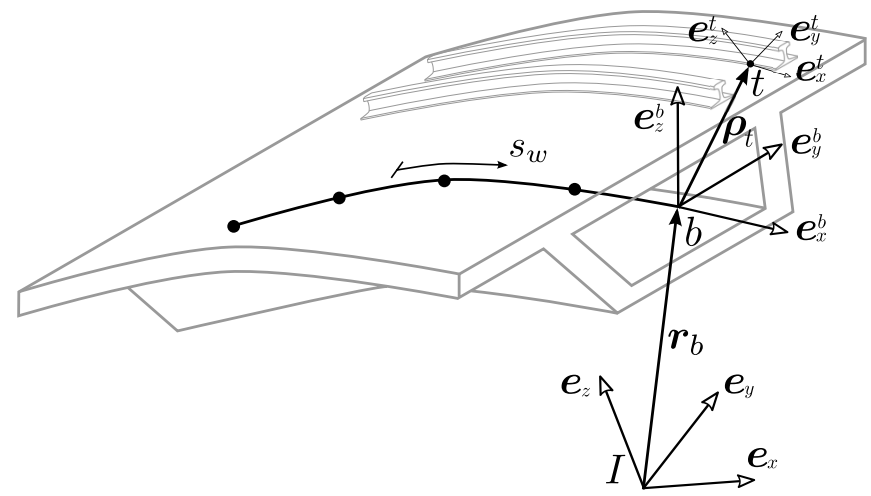

(a)

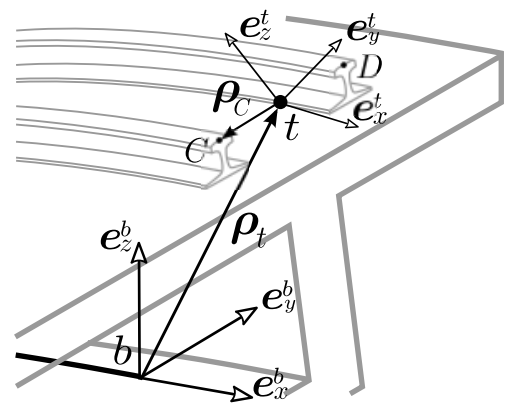

(b)

Figure 12: Reference frames and vectors for track kinematics: intermediate frame attached to the deck section $\left\{b, \boldsymbol{e}_{i}^{b}\right\}$ and the track coordinate system $\left\{t, \boldsymbol{e}_{i}^{t}\right\}$

initial position vector of the deck section. In the same way, rotation parameters will be interpolated as

$$
\boldsymbol{\theta}_{b}=\boldsymbol{\theta}_{b 0}+\mathbf{T}_{\theta}\left(s_{w}\right) \mathbf{q}^{B},
$$

where $\mathbf{T}_{\theta}\left(s_{w}\right)$ is the rotations interpolation operator and $\boldsymbol{\theta}_{b 0}$ the initial values of rotation parameters. The above expression contains the implicit assumption of small rotations for the bridge deck, for which case the rotation vectors may be interpolated linearly, as opposed to finite rotations which would require an interpolation of the exponential mapping.

\subsection{Wheelset-track interaction}

In order to compute the contact forces between wheels and rails the problem may be split in three consecutive stages:

1. Contact geometry: the main geometric variables involved in the problem are computed;

2. Normal contact: the dimensions and shape of the contact area and the normal stress distribution are determined;

3. Tangential contact: the resultant forces and moment of the tangential stresses, which appear as a consequence of the rolling contact, are obtained.

Assuming that the material properties of wheel and rail are the same (material symmetry), the normal and tangential problems may be considered uncoupled [19] and solved consecutively after the determination of the geometric variables.

Contact geometry. - The geometric problem relies on the key assumption that both the track section and the wheelset are supposed to move as planar rigid bodies within 
the plane cross section of the bridge (i.e. perpendicular to vector $\boldsymbol{e}_{x}^{b}$, Figure 12). Under this assumption, yaw rotation is neglected when assessing the main geometric variables involved in the wheel-rail contact. For a high-speed train running on a straight track, which is the case considered in this work, yaw rotation remains small and this approximation may be considered reasonable. Under this assumption the relative displacements between the wheelset and the track may be defined by 3 coordinates, the lateral and vertical relative displacements ( $\Delta y_{w}$ and $\Delta z_{w}$ respectively) and the relative rotation within the cross section $\Delta \psi_{w}$. Furthermore, two additional hypotheses are assumed:

1. The contact between the wheel and the rail occurs at only one point (area) at each wheel;

2. No separation occurs between wheels and rails.

Under these hypotheses, the relative vertical displacement $\Delta \check{z}_{w}$ and rotation $\Delta \check{\psi}_{w}$, due to purely geometric considerations, can be computed as a function of the relative lateral displacement $\Delta y_{w}$ for given wheel and rail profiles (in Figure 13 these are plotted for the S1002 wheel and UIC60 rail profiles):

$$
\begin{aligned}
& \Delta \check{z}_{w}=\Delta \check{z}_{w}\left(\Delta y_{w}\right) \\
& \Delta \check{\psi}_{w}=\Delta \check{\psi}_{w}\left(\Delta y_{w}\right)
\end{aligned}
$$

The relative coordinates $\Delta \check{z}_{w}$ and $\Delta \check{\psi}_{w}$, the contact angles $\gamma$ (Figure 14), rolling radii $r$ and transversal curvatures at both wheels are stored in a lookup table, from which these geometric variables will be obtained by interpolation for a given value of $\Delta y_{w}$.
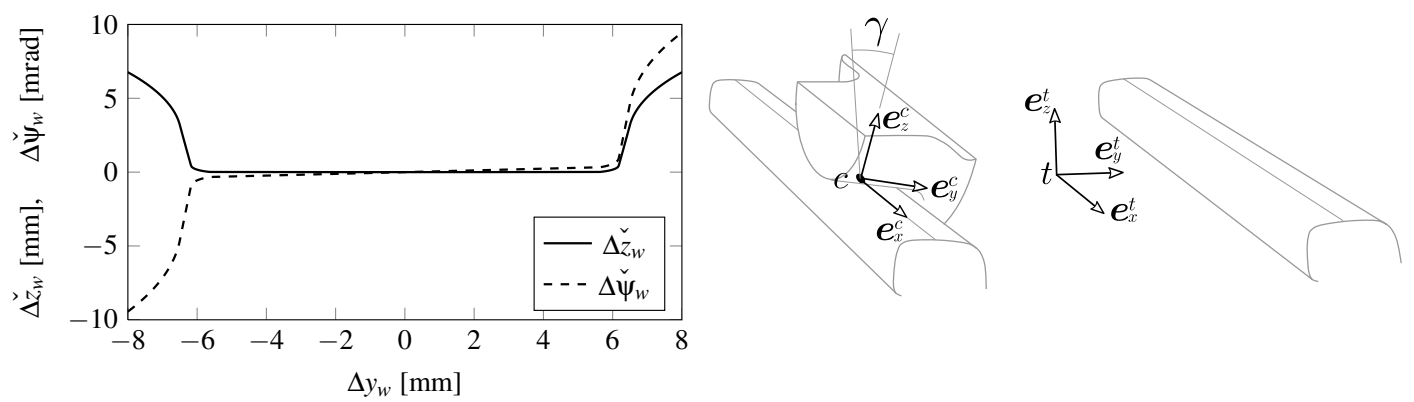

Figure 13: Compatible relative vertical Figure 14: Contact reference frame motion $\Delta \check{z}_{w}$ and rotation $\Delta \check{\psi}_{w}$ for $\operatorname{S} 1002\left\{C, \boldsymbol{e}_{i}^{c}\right\}$ and definition of angle $\gamma$ at conwheel profile and UIC60 rail tact point of one wheel

Normal and tangential contact forces. - At every wheel-rail pair a single hertzian contact [15] is assumed, for which the contact area is considered to be an ellipse with 
major and minor semiaxes $a$ and $b$ respectively. The normal stress distribution is assumed to be an ellipsoid whose resultant is the normal contact force $N$. The wheel and rail curvatures at the contact point may be computed as a function of $\Delta y_{w}$ as shown above. From these one may compute their mechanical properties, the resultant normal force $N$, the ellipse semiaxes $a$ and $b$ and the normal stress distribution, according to Hertz theory.

The solution for the tangential contact forces at each wheel contact is a complex nonlinear problem for which a reference solution may taken as Kalker's exact threedimensional rolling contact theory [18]. The coupled simulation of trains on bridges will require numerous evaluations, at each time-step and each wheel of the train. In order to bring down computational costs to reasonable bounds while maintaining sufficient precision for the simulations, the simplified FastSim algorithm [17] is used here, involving a compromise between accuracy and computational cost. The FastSim method has been implemented by the authors as a user subroutine within the Abaqus software employed [28] (further details in [1]).

For a given friction coefficient $\mu$, the input variables for evaluation of tangential rolling forces are the the normal stress distribution, the ellipse semiaxes and the creepages, defined as $\boldsymbol{\xi}=\left[\xi_{x}, \xi_{y}, \xi_{r}\right]^{\mathrm{T}}$ which are defined as:

$$
\xi_{\{x, y\}}=\frac{\left(\boldsymbol{v}_{A}-\boldsymbol{v}_{C}\right) \cdot \boldsymbol{e}_{\{x, y\}}^{c}}{v} \quad \xi_{r}=\frac{\left(\boldsymbol{\omega}_{w}-\boldsymbol{\omega}_{t}\right) \cdot \boldsymbol{e}_{z}^{c}}{v},
$$

with $v$ the wheelset longitudinal velocity. The FastSim model involves a discretisation in strips within the contact ellipse and integration along each strip, as shown in Figure 15. In this figure a representative case for distribution of tangential stresses is shown also.
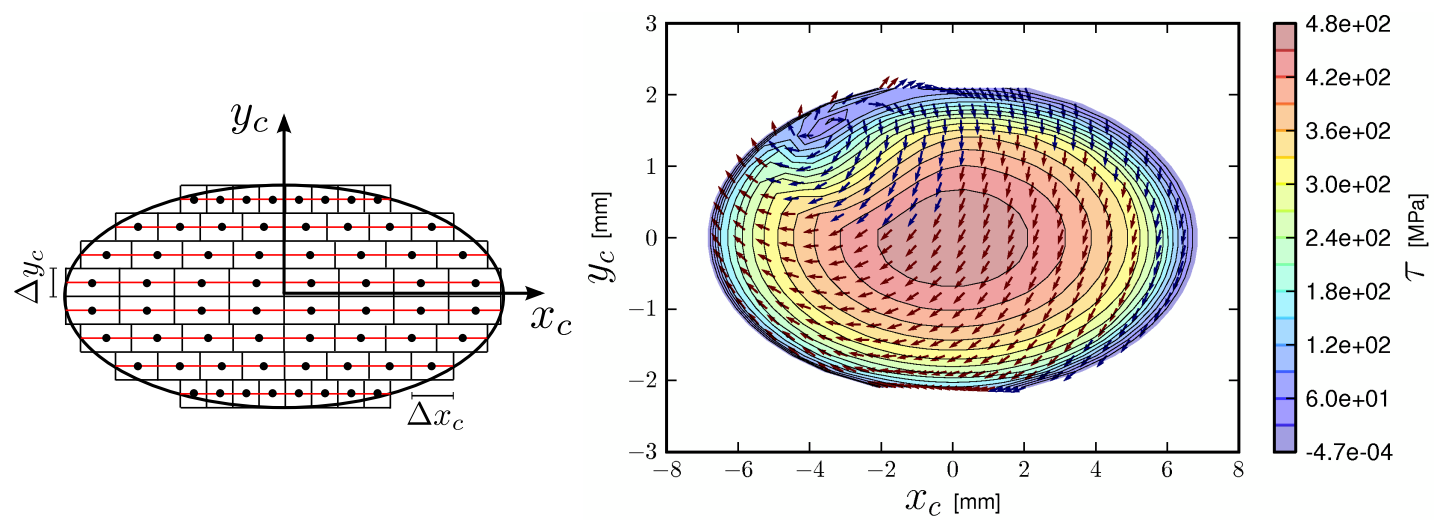

Figure 15: Discretisation of contact ellipse with FastSim and evaluation of tangential forces in rail-wheel contact

The resultants of the shear stress distribution at a point $A$ are the forces $T_{x}$ and $T_{y}$ and the moment $M_{z}$ whose directions are, respectively, $\boldsymbol{e}_{x}^{c}, \boldsymbol{e}_{y}^{c}$ and $\boldsymbol{e}_{z}^{c}$ :

$$
\begin{aligned}
\boldsymbol{f}_{C, A} & =T_{x} \boldsymbol{e}_{x}^{c}+T_{y} \boldsymbol{e}_{y}^{c}+N \boldsymbol{e}_{z}^{c}, \\
\boldsymbol{m}_{C, A} & =M_{z} \boldsymbol{e}_{x}^{c},
\end{aligned}
$$


Finally, in order to establish the geometric compatibility between wheels and rails set in equation (15), two constraint equations are defined at every wheelset:

$$
\left\{\boldsymbol{\phi}_{w}\right\}=\left\{\begin{array}{c}
\Delta z_{w}-\Delta \check{z}_{w}\left(\Delta y_{w}\right) \\
\Delta \psi_{w}-\Delta \check{\psi}_{w}\left(\Delta y_{w}\right)
\end{array}\right\}=\left\{\begin{array}{l}
0 \\
0
\end{array}\right\} .
$$

These constraints are enforced through a penalty method, with coefficients computed by a linearization of the Hertz contact.

\subsection{Vehicle-bridge system dynamics}

Considering wheelset contact forces and moments from (17) $\left(\boldsymbol{f}_{C}, \boldsymbol{m}_{C}\right)$, applied external loads $\left(\boldsymbol{f}_{E}, \boldsymbol{m}_{E}\right)$ and loads transmitted by the suspension systems $\left(\boldsymbol{f}_{S}, \boldsymbol{m}_{S}\right)$, the Newton-Euler equations for a single wheelset can be written as

$$
\begin{aligned}
m \ddot{\boldsymbol{r}}_{w}+\boldsymbol{f}_{S} & =\boldsymbol{f}_{E}+\boldsymbol{f}_{C}, \\
\boldsymbol{J} \dot{\boldsymbol{\omega}}_{w}+\boldsymbol{\omega}_{w} \times\left(\boldsymbol{J} \boldsymbol{\omega}_{w}\right)+\boldsymbol{m}_{S} & =\boldsymbol{m}_{E}+\boldsymbol{m}_{C},
\end{aligned}
$$

being $m$ the mass and $\boldsymbol{J}$ the inertia tensor for the wheelset.

For a general case of parametrization of rotations $\mathbf{G}$ as defined in (11), equation (19b) can be expressed as

$$
\boldsymbol{J} \mathrm{G} \ddot{\boldsymbol{\theta}}_{v}+\underbrace{\boldsymbol{J} \dot{\mathrm{G}} \dot{\boldsymbol{\theta}}_{v}+\boldsymbol{\omega}_{w} \times\left(\boldsymbol{J} \boldsymbol{\omega}_{w}\right)}_{\boldsymbol{m}_{Q}}+\boldsymbol{m}_{S}=\boldsymbol{m}_{E}+\boldsymbol{m}_{C},
$$

where the quadratic velocity terms have been included within the term $\boldsymbol{m}_{Q}$. The wheelset dynamic set of equations (19) may be assembled as

$$
\mathbf{M}^{w} \ddot{\mathbf{q}}^{w}+\mathbf{F}_{I}^{w}=\mathbf{F}_{E}^{w}+\mathbf{F}_{C}^{w},
$$

being

$$
\left[\mathbf{M}^{w}\right]=\left[\begin{array}{cc}
m \mathbf{1} & 0 \\
0 & \boldsymbol{J} \mathbf{G}
\end{array}\right], \quad\left\{\mathbf{q}^{w}\right\}=\left[\begin{array}{ll}
\boldsymbol{r}_{w} & \boldsymbol{\theta}_{v}
\end{array}\right]^{\mathrm{T}},
$$

and similarly $\mathbf{F}_{I}^{w}, \mathbf{F}_{E}^{w}, \mathbf{F}_{C}^{w}$ the assembled force vectors.

Employing standard multibody dynamics models for the remaining of the vehicle, these equations may be assembled into a full system of equations for the complete vehicle. On the other hand, the discretised equations for the bridge structural dynamics may be obtained following standard finite element procedures, and expressed in a similar fashion. Finally, the two nonlinear coupled sets of differential equations may be written as

$$
\begin{aligned}
& \mathbf{M}^{B} \ddot{\mathbf{q}}^{B}+\mathbf{F}_{I}^{B}=\mathbf{F}_{E}^{B}+\mathbf{F}_{C}^{B}, \\
& \mathbf{M}^{V} \ddot{\mathbf{q}}^{V}+\mathbf{F}_{I}^{V}=\mathbf{F}_{E}^{V}+\mathbf{F}_{C}^{V},
\end{aligned}
$$

where the superscript $B$ is referred to the bridge and $V$ to the vehicles, $\left(\mathbf{F}_{I}^{B}, \mathbf{F}_{I}^{V}\right)$ are the internal force vectors, $\left(\mathbf{F}_{E}^{B}, \mathbf{F}_{E}^{V}\right)$ the external loads and $\left(\mathbf{F}_{C}^{B}, \mathbf{F}_{C}^{V}\right)$ the contact force 
vectors. For the bridge the internal force vector corresponds to the forces and moments which appear as a consequence of the structural deformation. In the case of vehicles, forces and moments produced by suspension systems and quadratic velocity terms are included in this vector.

The interaction forces and moments of every wheelset are arranged in $\mathbf{F}_{C}^{V}$. For the bridge, interaction forces applied on the track are extrapolated to the corresponding nodal coordinates of finite element model and assembled in $\mathbf{F}_{C}^{B}$. These vectors establish the coupling between the equations of both subsystems.

The nonlinear set of differential equations (23) may be solved in time using an implicit integration method. In this work the HHT- $\alpha$ algorithm [16] has been used, included in Abaqus software [28]. This method has a good stability and robustness for the coupled problems described, and includes an inherent tunable numerical damping for the high frequency noise. The constraints inherent to the multibody subsystem are solved efficiently with augmented lagrangian procedures.

\section{Applications in lateral dynamics}

\subsection{Vehicle running on continuous deck bridge}

Two representative applications of the proposed models will be shown. First the response of a representative high-speed vehicle when it crosses over a multi-span bridge with continuous deck is analyzed. The mechanical data for the vehicle are detailed in Appendix A.

The structure is a single track continuous bridge consisting of six equal spans of $L=50 \mathrm{~m}$ each. The bridge is supported on two end abutments and five intermediate piers. Torsional rotation is allowed at the piers but constrained at the abutments. The deck cross section properties are uniform along the bridge length, see Appendix A. The first lateral and vertical bending eigenfrequencies are equal, of value $2.18 \mathrm{~Hz}$; the first torsion eigenfrequency is $1.10 \mathrm{~Hz}$. Euler-Bernoulli beam elements of $1 \mathrm{~m}$ length with linear elastic behaviour have been used.

The vehicle runs at a constant velocity of $100 \mathrm{~km} / \mathrm{h}$, with a lateral transient wind gust load defined by a chinese hat function [5] applied, with maximum value $F_{\max }=$ $270 \mathrm{kN}$ and gust duration $\tau=0.1 \mathrm{~s}$ (Figure 16). This load is applied on the vehicle car-body along $y$ direction (transversal) when the last wheelset of the vehicle enters the bridge.

In Figure 17 the lateral response of the last wheelset of the vehicle when it crosses the bridge is shown, compared with the case for a perfectly rigid track (i.e. no structure). It can be seen that wheel flanges contact the lateral part of rail heads, the limits are indicated in the graph with dotted lines. We remark that for assessment of these running safety scenarios a nonlinear model such as proposed here is essential, as linear models cannot reproduce wheel-flange impacts.

Figure 18 shows the lateral response of the vehicle car-body and Figure 19, the 

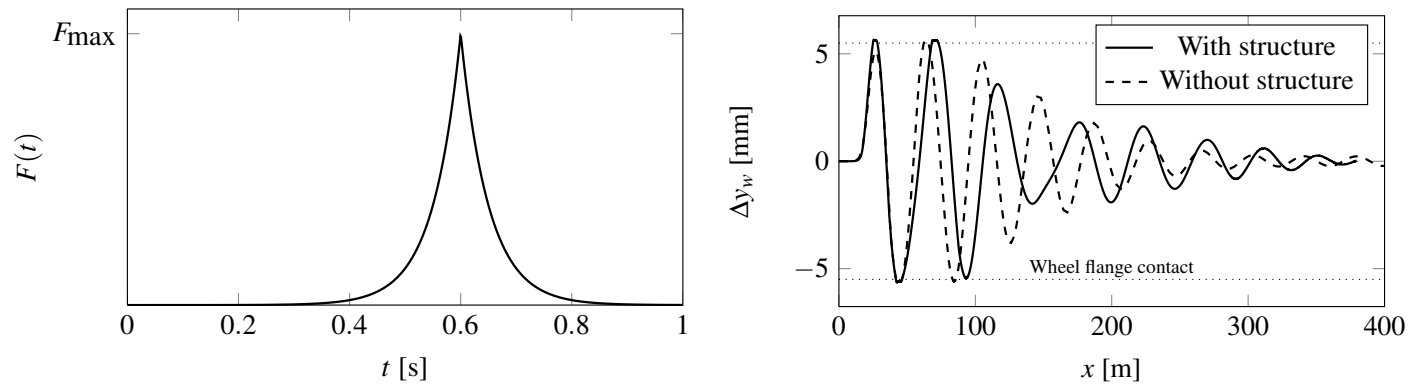

Figure 16: Lateral force history on vehicle Figure 17: Lateral response of last car-body: wind gust load corresponding wheelset; dotted lines indicate limit for to a "chinese hat" function wheel flange contact
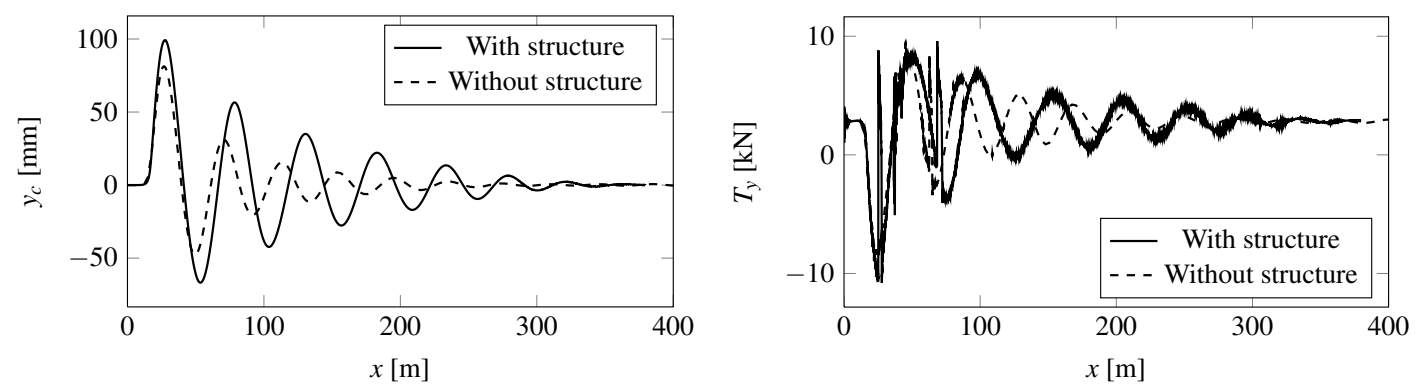

Figure 18: Lateral response of the car- Figure 19: Tangential contact forces at the body under an applied wind gust load left wheel of the last wheelset, showing peaks for wheel-flange contact

tangential force $T_{y}$ time history. This force is expressed at each instant in the local tangent plane to the whee contact (i.e. frame $\left\{C, \boldsymbol{e}_{i}^{c}\right\}$ ) of the left wheel of the last vehicle wheelset; it cannot be interpreted as a lateral load.

Figure 17 shows a significantly different response for wheelset displacements when the structure flexibility is taken into account: not only in terms of amplitude of oscillations, but also of frequency. A similar remark can be made for the car-body displacements, Figure 18. Moreover, contact forces in Figure 19 exhibit peaks which correspond to the flange impacts, these impacts differ significantly in both models.

\subsection{Application for viaduct "Arroyo las Piedras"}

A second application is performed for a real bridge within a new HS line, the "Arroyo las Piedras" viaduct, in operation in the Córdoba-Málaga high speed line. This is a long viaduct (total length $1209 \mathrm{~m}$ ), with a double-track composite steel-concrete continuous deck beam, supported on concrete piers with pot-type bearings. The spans of the deck are of $65 \mathrm{~m}$, and the section has upper and lower concrete slabs performing a so-called double composite action, with special provisions for ensuring adequate torsional stiffness. The tallest piers are of $94 \mathrm{~m}$ height. The first natural frequency 
of this viaduct is $0.313 \mathrm{~Hz}$ and corresponds to a lateral deformation mode (figure 20). More complete details of the structure may be found in [20].

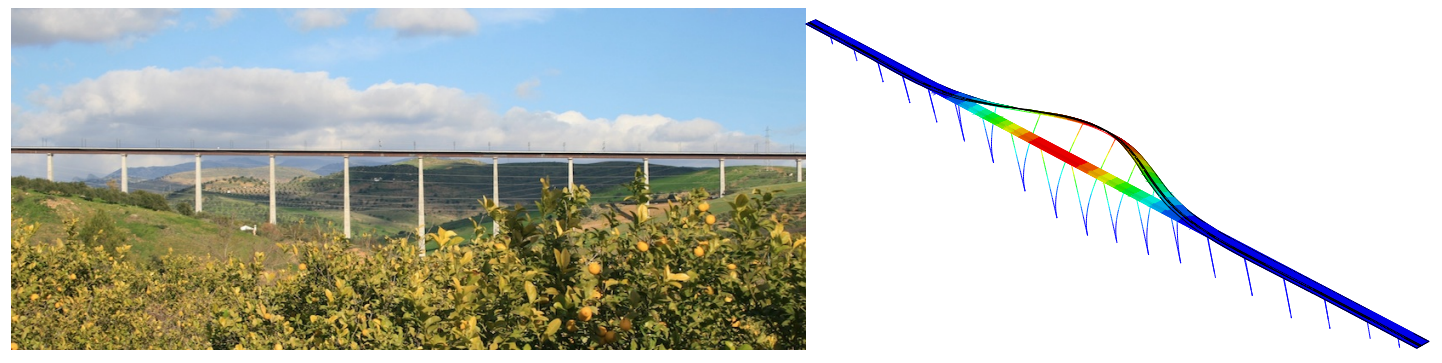

Figure 20: Viaducto "Arroyo las Piedras" in Córdoba-Málaga HS line: first mode of vibration $0.313 \mathrm{~Hz}$

As described above, the model for the viaduct is based on 3D beams with appropriate kinematic constraints. The Rayleigh method has been used for the damping matrix of the structure subsystem, with $0.5 \%$ damping centered in the two first natural frequencies. The train that has been used in the calculations is an approximation of the Siemens ICE 3 composed of 8 cars, each of 24.775 m length. The ICE3 is a multiple unit (distributed power) train, and all cars are supposed to have the same geometrical and mechanical properties.

Calculations have been carried out for train speeds of 250,300 and $350 \mathrm{~km} / \mathrm{h}$, with several models:

(1) Bridge only model with moving loads, consisting only of the bridge dynamic subsystem, with the vehicle wheelsets simplified as moving loads of fixed magnitude. This amounts to neglecting the dynamic effects of vehicle vibration, and serves as a basic result with which to compare the influence of the vehicle vibration on the results. It also serves the purpose of obtaining a so-called virtual path for the wheelsets of the vehicles, which can be later applied to these in a sequential approach to the vehicle-bridge dynamics: the bridge history of displacements is obtained in a first step, and these histories are then applied in a second step to the vehicle wheelsets to obtain the response of the train.

(2) Vehicle model, consisting only of the vehicle subsystem, in two different scenarios:

(a) Vehicle on rigid track (i.e. no bridge) with prescribed profiles of irregularities. This model will enable to compare the influence of the bridge deformation on the vibrations of the vehicle.

(b) Vehicle on virtual path, as described above, this path results from previous analysis of the bridge with moving loads. The geometric track irregularities are added to the virtual path in order to consider their effect on the vehicle. 
(3) Bridge-Vehicle model, performing the calculation for the global coupled system with wheel-rail contact interaction. In this case, two scenarios have been considered:

(a) Model with interaction but without track irregularities

(b) Model with interaction and with track irregularities

Following we show only the results for train speed of $v=350 \mathrm{~km} / \mathrm{h}$, as they correspond to the greatest effects. Firstly we present results for the deformation of the bridge deck: displacements and rotations at the center of span 11, corresponding to the tallest pier, are shown in figure 21. These correspond to the three different scenarios defined above, the cases enumerated as $1,3 \mathrm{a}$ and $3 \mathrm{~b}$. It may be clearly seen that the influence of the vehicle vibration and of the track irregularities on the bridge deformation is negligible. It is also seen that these deformations are small, with maximum lateral displacement of $9 \mathrm{~mm}$, which for a viaduct of $1209 \mathrm{~m}$ length is very small.
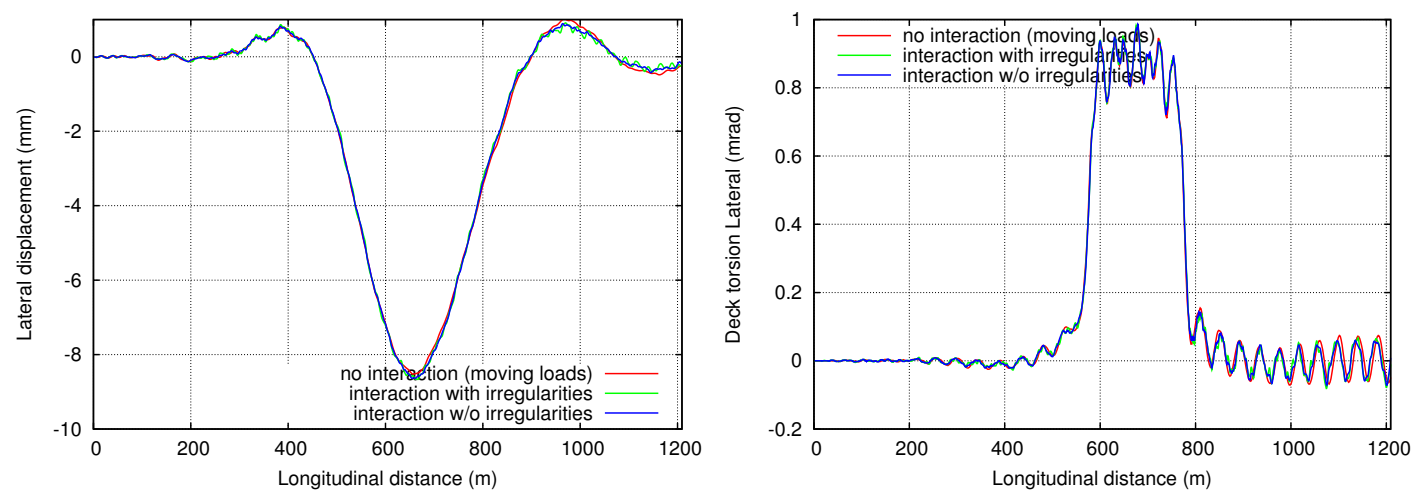

Figure 21: Displacements and torsional rotation of bridge deck at center of span 11 of Arroyo de las Piedras viaduct, for $v=350 \mathrm{~km} / \mathrm{h}$ train speed.

Regarding the response of the vehicle, the accelerations of vehicle body on coach 4 are shown in figure 22. Four scenarios are shown, as defined in section 4.2, the cases enumerated as $2 \mathrm{a}, 2 \mathrm{~b}, 3 \mathrm{a}$ and $3 \mathrm{~b}$. Maximum accelerations experienced are in the order of $0.2-0.3 \mathrm{~m} / \mathrm{s}^{2}$. We remark that very clearly irregularities are the main cause responsible for vehicle vibrations, as in the case $2 \mathrm{a}$ accelerations are negligible compared to other cases with irregularities. In other words, the vehicle body accelerations attributable to deformation of the bridge are of the order of $0.05 \mathrm{~m} / \mathrm{s}^{2}$.

\section{Conclusion}

The dynamic effects of high-speed trains on viaducts are important issues for the design of the structures, as well as for the consideration of safe running conditions of the trains. An adequate analysis of the resonant conditions and effects on railway bridges 

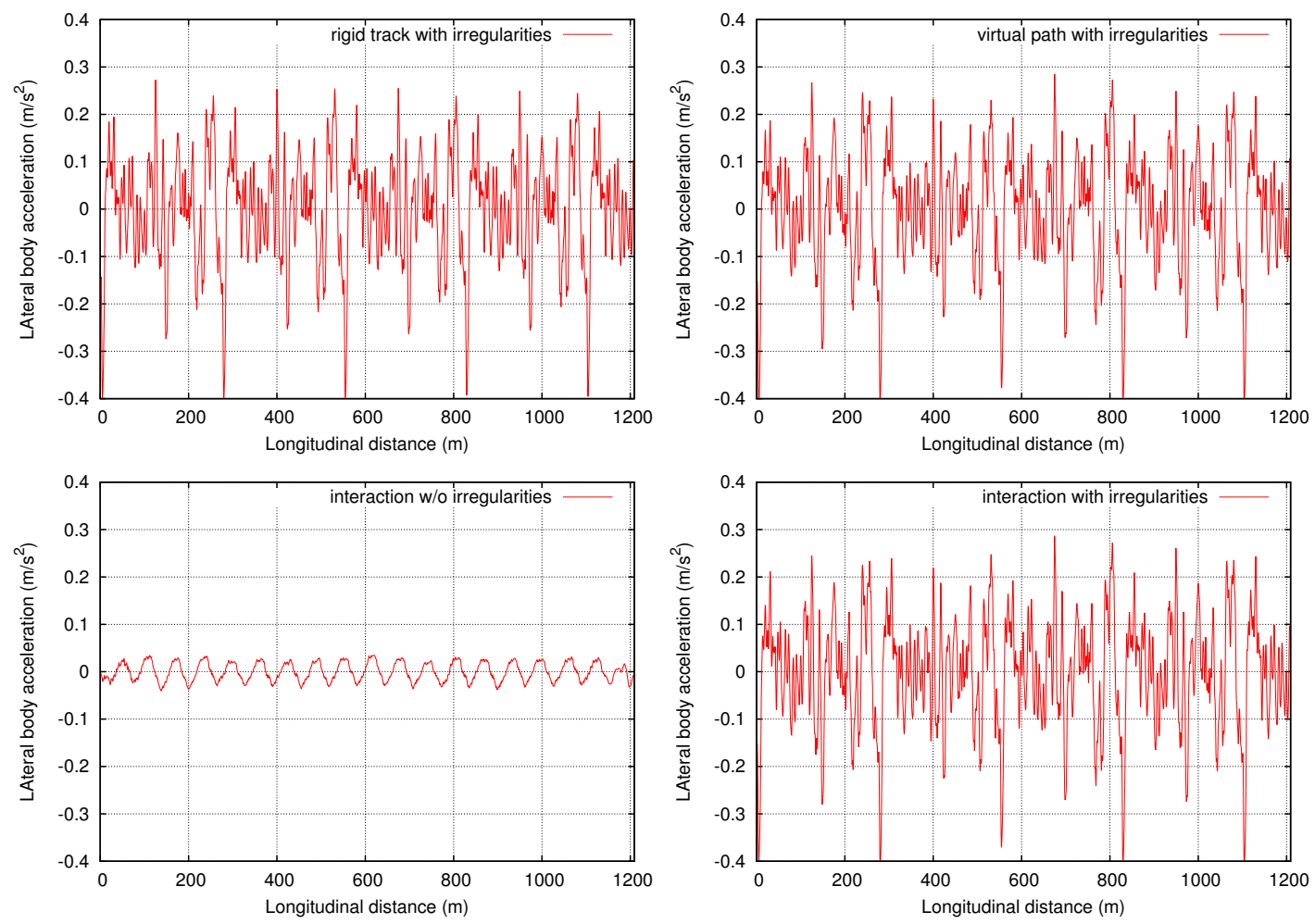

Figure 22: Acceleration of coach body over Arroyo de las Piedras Viaduct, for $v=$ $350 \mathrm{~km} / \mathrm{h}$ train with different models

is a key aspect for the design of bridges, which may be of special relevance in short span bridges. Some aspects such as the longitudinal distribution of loads, the number of modes for calculation and the consideration of interaction with the vehicles are discussed.

The study of lateral dynamics of running trains on bridges is of importance mainly for the safety of the traffic on laterally compliant bridges. These studies require 3D coupled vehicle-bridge models and consideration of wheel to rail contact. A fully nonlinear coupled model is proposed here, described in absolute coordinates and incorporated into a commercial finite element framework. The applications presented demonstrate the relevance of the coupling effect between vehicle and bridge, as well as for considering nonlinear contact wheel-rail models.

\section{Acknowledgments}

The authors are grateful for support from Ministerio de Ciencia e Innovación of Spanish Government in the project Integración de la Monitorización de Viaductos Ferroviarios en el Sistema de Gestión y Mantenimiento de Infraestructuras "VIADINTEGRA" (IPT-370000-20190-012), of the subprogram INNPACTO. The authors acknowledge also the support from the Technical University of Madrid, Spain. 


\section{References}

[1] P. Antolín, J.M. Goicolea, M.A. Astiz, "Strategies for Modeling Train-Bridge Lateral Dynamic Interaction”, in H. Xia, G. De Roeck, J.M. Goicolea (Editors), Bridge Vibration and Controls: New Research, Chapter 6, page In press. Nova Science Publishers, Inc., Hauppauge, NY, 2012, ISBN 978-1-62100-868-2.

[2] P. Antolin, J.M. Goicolea, J. Oliva, M.A. Astiz, "Nonlinear train-bridge lateral interaction using a simplified wheel-rail contact method within a finite element framework", Journal of Computational and Nonlinear Dynamics, 2012, In press.

[3] CEN, EN1991-2:2003 Eurocode 1 - Actions on structures, Part 2: Traffic loads on bridges, European Committee for Standardization, september 2003.

[4] CEN, EN1990:2002/A1:2005 Eurocode 0 - Basis of Structural Design, Ammendment A1; Annex A2, Application for bridges, European Committee for Standardization, december 2005.

[5] CEN, EN14067-6: Railway applications - Aerodynamics - Part 6: Requirements and test procedures for cross wind assessment, European Committee for Standardization, 2010.

[6] R. Clough, J. Penzien, Dynamics of Structures, Mac Graw-Hill, 1993.

[7] M. de Fomento, IAPF-07: Instrucción sobre las acciones a considerar en el proyecto de puentes de ferrocarril, Government of Spain, 2007.

[8] R. Dias, J. Goicolea, F. Gabaldon, M. Cuadrado, J. Nasarre, P. Gonzalez, "A study of the lateral dynamic behaviour of high speed railway viaducts and its effect on vehicle ride comfort and stability", in K.. Frangopol (Editor), Bridge Maintenance, Safety, Management, Health Monitoring and Informatics, pages 724-735. IABMAS08: Fourth International Conference on Bridge Maintenance, Safety and Management, Taylor \& Francis Group London, Seoul, 14-16 jul 2008, ISBN 978-0-415-46844-2.

[9] J. Domínguez Barbero, Dinámica de puentes de ferrocarril para alta velocidad: mtodos de cálculo y estudio de la resonancia, $\mathrm{PhD}$ thesis, Technical University of Madrid, 2001, http://oa.upm.es/1311.

[10] ERRI, Committee D181 final report: Forces Latérales sur les Ponts Ferroviaires, European Railway Research Institute, Utrecht, The Netherlands, 1996.

[11] ERRI, Committee D214 final report: Design of Railway Bridges for Speed up to $350 \mathrm{~km} / \mathrm{h}$; Dynamic loading effects including resonance, European Railway Research Institute, Utrecht, The Netherlands, 1998.

[12] C. Esveld, Modern Railway Track, MRT-Productions, The Netherlands, 2 edition, 2001. 
[13] European Railway Agency, Directive 96/48/EC Interoperability of the TransEuropean High Speed Rail System; Technical Specification for Interoperability, Infrastructure Sub-System, Official Journal of the European Union, march 2008.

[14] W. Guo, H. Xia, Y. Xu, "Running safety analysis of a train on the Tsing Ma Bridge under turbulent winds", Earthquake Engineering and Engineering Vibration, 9(3): 307-318, 2010.

[15] H. Hertz, "Über die berührung fester elasticher körper and über die härtean”, $J$. für reine und agewandte Mathematik, 92: 156-171, 1882.

[16] H.M. Hilber, T.J.R. Hughes, R.L. Taylor, "Improved numerical dissipation for time integration algorithms in structural dynamics", Earthquake Engineering \& Structural Dynamics, 5: 283-292, 1977.

[17] J.J. Kalker, "A Fast Algorithm for the Simplified Theory of Rolling Contact", Vehicle System Dynamics, 11(1): 1-13, 1982, ISSN 0042-3114, URL http: / /www. informaworld.com/10.1080/00423118208968684.

[18] J.J. Kalker, "The principle of virtual work and its dual for contact problems", Ingenieur-Archiv, 56(6): 453-467, 1986.

[19] J.J. Kalker, Three-Dimensional Elastic Bodies in Rolling Contact (Solid Mechanics and Its Applications), Springer, 1990, page 344.

[20] F. Millanes, J. Pascual, M. Ortega, “'Arroyo de las Piedras' viaduct: The first composite steelconcrete high speed railway bridge in Spain", Structural Engineering International, 17(4): 292-297, 2007.

[21] J. Nasarre, "Serviceability limit states in relation to the track in railway bridges", in R. Calçada, et al. (Editors), Bridges for High-Speed Railways, pages 211-220. Taylor \& Francis, London, 2009.

[22] D.V. Nguyen, K.D. Kim, P. Warnitchai, "Dynamic analysis of three-dimensional bridge-high-speed train interactions using a wheelrail contact model", Engineering Structures, 31(12): 3090-3106, 2009.

[23] P.E. Nikravesh, Computer-Aided Analysis of Mechanical Systems, Prentice Hall, Inc., Englewood Cliffs, NJ, 1988, page 370.

[24] K. Popp, W. Schiehlen, Ground Vehicle Dynamics, Springer Berlin Heidelberg, Chennai, 1st edition, 2010, ISBN 978-3-540-68553-1, page 348.

[25] A.A. Shabana, K.E. Zaazaa, J.L. Escalona, J.R. Sany, "Development of elastic force model for wheel/rail contact problems", Journal of Sound and Vibration, 269(1-2): 295-325, Jan. 2004, ISSN 0022460X, URL http://dx.doi. org/10.1016/S0022-460x(03)00074-9. 
[26] A.A. Shabana, K.E. Zaazaa, H. Sugiyama, Railroad Vehicle Dynamics: A Computational Approach, CRC Press, 2008.

[27] J.C. Simo, L. Vu-Quoc, "The role of non-linear theories in transient dynamic analysis of flexible structures", Journal of Sound and Vibration, 119(3): 487508, Dec. 1987, ISSN 0022460X, URL http://dx.doi.org/10.1016/ $0022-460 \mathrm{X}(87) 90410-\mathrm{X}$.

[28] Simulia Ltd., Abaqus 6.10 User's manual, Providence, RI, 2010.

[29] SNCF, "New categories for defining the compatibility interface between multiple units and infrastructure; Definition of Reference Load Models for new Multiple Units", Technical report, Societé Nationale des Chemins de Fer, Département des Ouvrages d'Art, 6 avenue Francois Mitterrand, 93574 La Plaine St Denis, june 20, 2011, In the framework of CEN TC256 WG10 SG03 - Update of the EN15528.

[30] M.K. Song, H.C. Noh, C.K. Choi, "New three-dimensional finite element analysis model of high-speed train-bridge", Engineering Structures, 25: 1611-1626, 2003.

[31] M. Tanabe, H. Wakui, N. Matsumoto, H. Okuda, M. Sogabe, S. Komiya, "Computational model of a Shinkansen train running on the railway structure and the industrial applications", Journal of Materials Processing Technology, 140(1-3): 705-710, 2003.

[32] M. Tanabe, H. Wakui, M. Sogabe, N. Matsumoto, T. Y, "An efficient numerical model for dynamic interaction of high speed train and railway structure including post-derailment during and earthquake", in G. De Roeck, G. Degrande, G. Lombaert, G. Müller (Editors), 8th International Conference on Structural Dynamics, EURODYN 2011. K. U. Leuven, Leuven, Belgium, 2011.

[33] S.P. Timoshenko, Vibration problems in engineering, Van Nostrand, 1928.

[34] UIC, Code UIC 776-1: Charges a prendre en consideration dans le calcul des ponts-rails, Union Internationale des Chemins de Fer, 3 edition, jul 1979.

[35] UIC, Code UIC 776-1: Charges a prendre en consideration dans le calcul des ponts-rails, Union Internationale des Chemins de Fer, 5 edition, august 2006.

[36] H. Xia, N. Zhang, G.D. Roeck, "Dynamic analysis of high speed railway bridge under articulated trains", Computers \& Structures, 81: 2467-2478, 2003.

[37] Y.L. Xu, N. Zhang, H. Xia, "Vibration of coupled train and cable-stayed bridge systems in cross winds", Engineering Structures, 26: 1389-1406, 2004. 
[38] Y.B. Yang, J.D. Yau, Y.S. Wu, Vehicle-Bridge Interaction Dynamics: With Applications To High-Speed Railways, World Scientific Publishing Company, Singapore, 1st edition, 2004, ISBN 9812388478, page 530, URL http://www.amazon.com/Vehicle-Bridge-InteractionDynamics-Applications-High-Speed/dp/9812388478.

[39] N. Zhang, H. Xia, W. Guo, "Vehicle-bridge interaction analysis under highspeed trains", Journal of Sound and Vibration, 309(3-5): 407-425, 2008.

[40] N. Zhang, H. Xia, W.W. Guo, G. De Roeck, "A Vehicle-Bridge Linear Interaction Model and Its Validation", International Journal of Structural Stability and Dynamics, 10(02): 335, 2010.

\section{Appendix A: Vehicle and bridge mechanical properties}

\begin{tabular}{lcclcc}
\hline Item & Unit & Value & Item & Unit & Value \\
\hline$m_{c}$ & $\mathrm{~kg}$ & 53500.0 & $J_{c x}$ & $\mathrm{~m}^{4}$ & 70000.0 \\
$J_{c y}$ & $\mathrm{~m}^{4}$ & 2621500.0 & $J_{c z}$ & $\mathrm{~m}^{4}$ & 2621500.0 \\
$m_{b}$ & $\mathrm{~kg}$ & 3500.0 & $J_{b x}$ & $\mathrm{~m}^{4}$ & 560.0 \\
$J_{b y}$ & $\mathrm{~m}^{4}$ & 315.0 & $J_{b z}$ & $\mathrm{~m}^{4}$ & 1715.0 \\
$m_{w}$ & $\mathrm{~kg}$ & 1800.0 & $J_{w x}$ & $\mathrm{~m}^{4}$ & 1000.0 \\
$J_{w y}$ & $\mathrm{~m}^{4}$ & 100.0 & $J_{w z}$ & $\mathrm{~m}^{4}$ & 1000.0 \\
$k_{x 1}$ & $\mathrm{kN} / \mathrm{m}$ & 120000.0 & $k_{y 1}$ & $\mathrm{kN} / \mathrm{m}$ & 12500.0 \\
$k_{z 1}$ & $\mathrm{kN} / \mathrm{m}$ & 1200.0 & $c_{x 1}$ & $\mathrm{kN} \cdot \mathrm{s} / \mathrm{m}$ & 27.9 \\
$c_{y 1}$ & $\mathrm{kN} \cdot \mathrm{s} / \mathrm{m}$ & 9.0 & $c_{z 1}$ & $\mathrm{kN} \cdot \mathrm{s} / \mathrm{m}$ & 10.0 \\
$k_{x 2}$ & $\mathrm{kN} / \mathrm{m}$ & 12000.0 & $k_{y 2}$ & $\mathrm{kN} / \mathrm{m}$ & 240.0 \\
$k_{z 2}$ & $\mathrm{kN} / \mathrm{m}$ & 350.0 & $c_{x 2}$ & $\mathrm{kN} \cdot \mathrm{s} / \mathrm{m}$ & 600.0 \\
$c_{y 2}$ & $\mathrm{kN} \cdot \mathrm{s} / \mathrm{m}$ & 30.0 & $c_{z 2}$ & $\mathrm{kN} \cdot \mathrm{s} / \mathrm{m}$ & 20.0 \\
$h_{c}$ & $\mathrm{~m}$ & 1.4 & $h_{b}$ & $\mathrm{~m}$ & 0.5 \\
$r_{0}$ & $\mathrm{~m}$ & 0.46 & $d_{c}$ & $\mathrm{~m}$ & 17.375 \\
$d_{b}$ & $\mathrm{~m}$ & 2.5 & $d_{w}$ & $\mathrm{~m}$ & 0.753 \\
\hline
\end{tabular}

Table 1: Mechanical properties of the vehicle considered in Section 4.1. $m$ refers to masses, $J$ to rotary inertias, $k$ corresponds to suspension stiffnesses and $c$ to damping; subscripts $x, y$ and $z$ indicate the orientation of the suspension properties, and 1 and 2 are referred to primary and secondary suspensions; $c, b$ and $w$ correspond to car-body, bogies and wheelsets, respectively; $h_{c}$ and $h_{b}$ are the center of gravity heights of carbody and bogies; and $d_{c}$ is the longitudinal distance between two bogies of the same vehicle and $d_{b}$ between two wheelsets of the same bogie. 


\begin{tabular}{lcclcc}
\hline Item & Unit & Value & Item & Unit & Value \\
\hline$E$ & $\mathrm{GPa}$ & 30.0 & $G$ & $\mathrm{GPa}$ & 12.5 \\
$A$ & $\mathrm{~m}^{2}$ & 1.0 & $J_{x x}$ & $\mathrm{~m}^{4}$ & 0.189 \\
$J_{y y}$ & $\mathrm{~m}^{4}$ & 1.0 & $J_{z z}$ & $\mathrm{~m}^{4}$ & 1.0 \\
$\rho$ & $\mathrm{kg} / \mathrm{m}^{3}$ & 2500.0 & $e_{z}$ & $\mathrm{~m}$ & 1.50 \\
\hline
\end{tabular}

Table 2: Mechanical properties of bridge deck cross section considered in section 4.1, being $E$ and $G$ the Young and shear modulus; $A$ the cross section area; $J_{x x}, J_{y y}$ and $J_{z z}$ the moments of inertia corresponding to the longitudinal, transversal and vertical directions, respectively; $\rho$ the material density and $e_{z}$ the vertical offset of the track center as explained in Section 3.2. 